\title{
The frontopolar cortex and human cognition: Evidence for a rostrocaudal hierarchical organization within the human prefrontal cortex
}

\author{
KALINA CHRISTOFF and JOHN D. E. GABRIELI \\ Stanford University, Stanford, California
}

\begin{abstract}
Numerous brain lesion and functional neuroimaging studies have suggested that the dorsolateral and frontopolar prefrontal regions are involved in complex cognitive processes subserving thought and memory. However, previously proposed functional subdivisions of prefrontal function have concentrated predominantly on posterior prefrontal cortex, including the dorsolateral, ventral, and medial regions. Far less consideration has been given to characterizing the psychological processes mediated by the frontopolar cortex. Here we review published neuroimaging studies of reasoning and episodic memory, two domains in which the frontopolar cortex has been frequently activated. The results suggest that dorsolateral prefrontal cortex is involved when externally generated information is being evaluated, whereas the frontopolar cortex becomes recruited when internally generated information needs to be evaluated. A hierarchical model of prefrontal function is proposed in which dorsolateral and frontopolar regions are serially recruited as a reasoning or memory task requires evaluation of internally generated information.
\end{abstract}

The prefrontal cortex is known to be essential for complex cognitive processing, but its functions have been defined in mostly general terms. One approach to a more precise functional definition has been to regard the prefrontal cortex as a heterogeneous region, composed of specialized subregions with different functional roles. Indeed, cytoarchitectonic studies in the beginning of the 20th century (Brodmann, 1908; Campbell, 1905; Elliott Smith, 1907; Vogt, 1906), as well as recent neuroanatomic studies (Pandya \& Barnes, 1987), neurophysiological (di Pellegrino \& Wise, 1991; Rosenkilde, 1979) and neurocircuitry studies (Alexander, DeLong, \& Strick, 1986; Barbas \& Pandya, 1991; Pandya \& Barnes, 1987) have suggested that the prefrontal cortex should be subdivided into several structurally and functionally different subregions. A number of regional specifications have been proposed, from Broca's original localization of the inferior prefrontal cortex as an area essential for the production of speech, to recently proposed functional specializations of specific prefrontal subregions such as the ventromedial (Damasio, 1996), orbitofrontal (Rolls, 1996), and dorsolateral (Goldman-Rakic, 1987; Petrides, 1991).

Support for this article came from National Institute of Aging Grants AG12995 and AG1121 to J.D.E.G. and a New Democracy Fellowship award to K.C. We thank Shelley Zulman for help with preparing the tables, Vivek Prabhakaran for providing the foci for the RPM study, Ewart Thomas for advice on statistical issues, and Matthew Brett for providing the program used to plot foci onto brain renderings. We are also grateful to Chandan Vaidya and two anonymous reviewers, who provided helpful suggestions regarding an earlier version of the article. Correspondence should be addressed to K. Christoff, Department of Psychology, Jordan Hall, Main Quad, Stanford University, Stanford, CA 94305 (e-mail: kalina@psych.stanford.edu).
Some analyses have focused on contrasting one subregion to another (for instance, D'Esposito et al., 1998; Owen, Evans, \& Petrides, 1996; Petrides, 1994) in order to clarify the type of processing for which each subregion is specialized.

Most considerations of regional specialization, however, have concentrated on the posterior prefrontal cortex, including the dorsolateral, ventral, medial, and orbitofrontal regions. There has been far less consideration of the anterior-most part of the prefrontal cortex, usually referred to as the frontopolar (or rostrolateral) prefrontal cortex. Neuropsychological studies of the frontal lobes have often included patients with lesions involving the frontopolar cortex, but have been unable to adequately control for differences in the location of lesions in the anterior-posterior dimension (Stuss \& Benson, 1986) and currently there is no definitive lesion data concerning the functional role of the frontopolar cortex (Baker et al., 1996). Similarly, neurophysiological and lesion studies with nonhuman primates have concentrated on the middorsal or other posterior prefrontal regions, without attributing any specific functional role to the frontopolar cortex.

With remarkable frequency, however, functional neuroimaging studies have detected frontopolar cortex activation when people perform complex cognitive tasks. Activation in this region has been reported for many reasoning tasks, such as the Tower of London (Baker et al., 1996), the Wisconsin Card Sorting Test (WCST; Berman et al., 1995; Goldberg et al., 1998; Nagahama et al., 1996), inductive and probabilistic reasoning tasks (Goel, Gold, Kapur, \& Houle, 1997; Osherson et al., 1998), and the Raven's Progressive Matrices Test (RPM; Prabhakaran, Smith, Desmond, Glover, \& Gabrieli, 1997). Frontopolar 
activations are also common when people perform memory tasks involving episodic retrieval (for reviews, see Cabeza et al., 1997; Nolde, Johnson, \& Raye, 1998; Nyberg, Cabeza, \& Tulving, 1996). Many of these studies report both dorsolateral and frontopolar activations, but few offer suggestions as to what different psychological operations are mediated by these anatomically distinct frontal regions (exceptions are Baker et al., 1996; and Koechlin, Basso, Pietrini, Panzer, \& Grafman, 1999).

In this article, we review the results from neuroimaging studies in the domains of reasoning and episodic memory retrieval and examine the evidence for a functional distinction within the prefrontal cortex in a rostrocaudal (anterior-posterior) direction. The review suggests that frontopolar cortex can be viewed as functionally distinct from the dorsolateral cortex. We propose that these two regions of the cortex form a hierarchical system specialized for the evaluation, monitoring, and manipulation of information held in working memory. More specifically, the dorsolateral prefrontal cortex is involved during processing of externally generated information, whereas the frontopolar cortex is additionally recruited during processing of internally generated information. Thus, the dorsolateral cortex is sufficient when the internally represented information being processed is or has recently been immediately present in the environment. On the other hand, the frontopolar cortex is recruited in addition to the dorsolateral when the internally represented information being acted on was not present in the environment and has been internally generated.

Although the present article will focus specifically on the dorsolateral and frontopolar cortical areas, the processes involved in reasoning and episodic memory retrieval are most likely subserved by an interconnected and widely distributed system of cortical and subcortical regions. A more complete understanding of these two prefrontal areas will ultimately require an appreciation of how they interact with other brain regions.

\section{Terminological Considerations}

Even though the terms frontopolar and dorsolateral, as defining regions of the prefrontal cortex, are used widely in the neuroimaging literature, there have been occasional inconsistencies among different researchers in relating these regions to Brodmann's (1908) classification of cortical areas. The extent of dorsolateral prefrontal cortex has been generally agreed upon as corresponding to Brodmann's areas (BA) 9 and 46, which include the middle parts of the superior and middle frontal gyri (Petrides $\&$ Pandya, 1994). The term dorsolateral is used to distinguish this region from the frontopolar cortex, which lies rostral to the dorsolateral (Petrides, 1996).

There has, however, been a lack of general agreement with respect to the anatomical extent of the frontopolar cortex. The most liberal approach is to classify as "frontopolar" all activations that fall within area 10 . However, this criterion makes it difficult to distinguish frontopolar cortex from medial prefrontal cortex (covered in part by the medial portion of area 10) and the orbitofrontal cortex (covered in part by the inferior-most portion of area 10). Moreover, area 10 varies across its medial, lateral, and orbital surface both in terms of cytoarchitectonics (Petrides \& Pandya, 1994) and in terms of functional connectivity (Pandya \& Barnes, 1987). Therefore, defining the frontopolar cortex as area 10 may be too general and may have contributed to the difficulties in precisely characterizing its functional specialization. In the analysis below, we have taken a more conservative approach by defining the frontopolar cortex as the lateral portion of area 10 , or the anterior parts of the middle and superior frontal gyri. In addition, the interim areas on the lateral borderline of area 10 (areas 10/46 and 10/9) are also classified as part of the frontopolar cortex.

\section{Distribution Analyses of Neuroimaging Studies}

In this article we present analyses of the distribution of stereotaxic coordinates of activation foci reported by neuroimaging studies in the domains of reasoning and episodic memory retrieval. These analyses were conducted in order to gain evidence as to what psychological processes may be mediated by the frontopolar cortex and, where possible, to reveal differences between task conditions associated with frontopolar and dorsolateral activations.

Inclusion criteria. We have attempted to review all published studies of reasoning and episodic retrieval that (1) reported stereotaxic coordinates and (2) reported either dorsolateral and/or frontopolar activation. The first of these two domains - the domain of reasoning--is not precisely defined. A certain degree of reasoning may be associated with many sorts of studies. Here, we review only studies that intentionally studied reasoning processes and employed standard problem-solving tasks.

Methodological considerations. In any review of neuroimaging literature, studies are likely to vary considerably not only in the specific experimental and baseline conditions but also in the way data are analyzed. The reviews we present are based on the reported local maxima because volumetric measures such as activation extent or cluster size may be more sensitive to variation in analysis parameters (Worsley, Marrett, Neelin, \& Evans, 1996). Local maxima, on the other hand, are useful for cross-study comparisons because differences in smoothing kernels or statistical power ought to have a minimal effect on their location. Nevertheless, there remain differences across studies in how anatomical and functional data are registered in standardized space, which could affect the location of prefrontal activations. Further, differences in statistical methods may result in differences in the control of Type I error (Aguirre, Zarahn, \& D'Esposito, 1997; Zarahn, Aguirre, \& D'Esposito, 1997), which in the present reviews could lead to spurious dorsolateral or frontopolar activations. Similarly, there could be differences in the control of Type II error, which in this case would lead to failures in detecting existing prefrontal activations. However, in spite of inevitable differences across studies, an integrative analysis of the reported locations 
of significant activation maxima can prove useful for revealing functional specialization of brain regions.

\section{FRONTOPOLAR CORTEX ACTIVATIONS}

\section{Distribution Analysis of Neuroimaging Studies of Reasoning}

In order to assess the extent to which frontopolar activation has been characteristic of reasoning tasks, we summarized activation foci reported across neuroimaging studies of reasoning. The studies used problem solving tasks such as the Tower of London, card sorting, inductive (or probabilistic) reasoning, and the RPM. Tables 1 and 2 list the studies along with details about the target and reference task, information on whether frontopolar and dorsolateral prefrontal cortex activation was reported, and the stereotaxic coordinates of the local maxima of activation reported by the studies. The stereotaxic coor-

Table 1

Reasoning and the Frontopolar Prefrontal Cortex

\begin{tabular}{|c|c|c|c|c|c|}
\hline Task & Study & Target Task & Reference Task & $\begin{array}{l}\text { Frontopolar } \\
\text { (BA 10) }\end{array}$ & $\begin{array}{c}\text { Dorsolateral } \\
\text { (BA 9/46) }\end{array}$ \\
\hline \multirow[t]{2}{*}{ Tower of London } & $\begin{array}{l}\text { Owen, Doyon, } \\
\text { et al., } 1996\end{array}$ & $\begin{array}{l}3-5 \text { move problems } \\
\text { (making moves) }\end{array}$ & $\begin{array}{l}\text { Touching indicated } \\
\text { screen positions }\end{array}$ & - & B \\
\hline & Baker et al., 1996 & $\begin{array}{l}2-5 \text { move problems } \\
\text { (minimum number of moves) }\end{array}$ & $\begin{array}{l}\text { Pressing a ball when } \\
\text { indicated }\end{array}$ & $\mathbf{R}$ & B \\
\hline \multirow[t]{5}{*}{ Card Sorting } & Berman et al., 1995 & Computerized WCST & Matching-to-sample & B & $\mathrm{R}$ \\
\hline & Nagahama et al., 1996 & Modified CST & Matching-to-sample & B & B \\
\hline & Rao et al., 1997 & Conceptual reasoning task & $\begin{array}{l}\text { Respond to a given } \\
\text { stimulus feature }\end{array}$ & $\mathbf{R}$ & - \\
\hline & Goldberg et al., 1998 & Computerized WCST & Matching-to-sample & $\mathbf{R}$ & B \\
\hline & Ragland et al., 1998 & Color slice WCST & Rest & - & B \\
\hline \multirow[t]{2}{*}{ Inductive Reasoning } & Goel et al., 1997 & Inductive reasoning & $\begin{array}{l}\text { Semantic sentence } \\
\text { comprehension }\end{array}$ & $\mathrm{L}$ & - \\
\hline & Osherson et al., 1998 & $\begin{array}{l}\text { Probabilistic (inductive) } \\
\text { reasoning }\end{array}$ & Language comprehension & $\mathbf{R}$ & - \\
\hline RPM & Prabhakaran et al., 1997 & $\begin{array}{l}\text { (1) Figural problems } \\
\text { (2) Analytic problems }\end{array}$ & $\begin{array}{l}\text { Match problems } \\
\text { Match problems }\end{array}$ & $\begin{array}{l}\mathbf{R} \\
\mathbf{R}\end{array}$ & $\begin{array}{l}\mathbf{R} \\
\mathbf{B} \\
\end{array}$ \\
\hline
\end{tabular}

Note-CST, cart sorting task; WCST, Wisconsin CST; RPM, Raven's Progresive Matrices Test; B, bilateral; R, right; L, left. Frontopolar and dorsolateral activations reported by neuroimaging studies (PET and fMRI) of reasoning. Only studies reporting stereotaxic coordinates are included. Dashes indicate that no activation was observed in the corresponding region. The study reported by Goel et al. (1998) is not included because of incomplete report of the stereotaxic coordinates of activation foci for the regions of interest.

Table 2

Stereotaxic Coordinates of the Local Maxima of Activation During Reasoning, Plotted in Figure 1

\begin{tabular}{|c|c|c|c|c|c|c|c|c|c|c|c|c|c|c|c|c|}
\hline \multirow[b]{3}{*}{ Task/Study } & \multicolumn{8}{|c|}{ Frontopolar Prefrontal Cortex (BA 10) } & \multicolumn{8}{|c|}{ Dorsolateral Prefrontal Cortex (BA 9, BA 46) } \\
\hline & \multicolumn{4}{|c|}{ Left Hemisphere } & \multicolumn{4}{|c|}{ Right Hemisphere } & \multicolumn{4}{|c|}{ Left Hemisphere } & \multicolumn{4}{|c|}{ Right Hemisphere } \\
\hline & $x$ & $y$ & $z$ & Area & $x$ & $y$ & $z$ & Area & $x$ & $y$ & $z$ & Area & $x$ & $y$ & $z$ & Area \\
\hline \multicolumn{17}{|l|}{ Tower of London } \\
\hline Owen, Doyon, et al., 1996 & - & - & - & - & - & - & - & - & -39 & 18 & 32 & (9) & 39 & 35 & 35 & (9) \\
\hline Baker et al., 1996 & - & - & - & - & 28 & 54. & -4 & $(10)$ & -42 & 26 & 32 & (9) & 36 & 28 & 32 & (9) \\
\hline \multicolumn{17}{|l|}{ Card Sorting Task } \\
\hline Berman et al., 1995 & -32 & 50 & 8 & (10) & 28 & 48 & 12 & $(10)$ & - & - & - & - & 40 & 28 & 20 & (46) \\
\hline Nagahama et al., 1996 & -26 & 54 & -8 & (10) & 28 & 50 & -8 & (10) & -42 & 22 & 32 & (9) & 30 & 24 & 28 & $(9 / 46)$ \\
\hline & & 54 & 12 & (10) & & & & & & & 40 & (9) & & & & \\
\hline Rao et al., 1997 & - & - & - & - & 38 & 43 & 19 & $(10 / 46)$ & - & - & - & $一$ & - & - & - & 一 \\
\hline Goldberg et al., 1998 & - & - & - & - & 30 & 58 & 8 & (10) & -46 & 34 & 28 & $(9 / 46)$ & $\begin{array}{l}26 \\
38\end{array}$ & $\begin{array}{l}24 \\
24\end{array}$ & $\begin{array}{l}32 \\
24\end{array}$ & $\begin{array}{r}(9) \\
(46)\end{array}$ \\
\hline Ragland et al., 1998 & - & - & 一 & - & - & - & - & - & -38 & 30 & 32 & (9) & 40 & 18 & 32 & (9) \\
\hline \multicolumn{17}{|l|}{ Inductive Reasoning } \\
\hline Goel et al., 1997 & -36 & 52 & 8 & (10) & - & - & - & - & - & - & - & - & - & - & - & - \\
\hline Osherson et al., 1998 & - & - & - & - & 26 & 40 & 16 & $(10 / 46)$ & - & - & - & - & - & - & - & - \\
\hline \multicolumn{17}{|l|}{ RPM } \\
\hline Prabhakaran et al., 1997, Exp. 1 & - & - & - & - & 47 & 50 & 4 & $(10 / 46)$ & - & - & - & - & 34 & 14 & 40 & (9) \\
\hline Prabhakaran et al., 1997, Exp. 2 & - & - & - & - & 42 & 49 & 12 & (10) & -35 & 31 & 20 & (46) & 52 & 12 & 40 & (9) \\
\hline & & & & & 41 & 50 & 20 & (10) & & & & & 48 & 26 & 32 & (9) \\
\hline & & & & & 28 & 52 & 24 & (10) & & & & & & & & \\
\hline
\end{tabular}

Note-The details of this table are the same as those for Table 1. All reported activation sites within the two regions of interest are listed. The originally reported stereotaxic coordinates were reclassified in the coordinate system of Talairach and Tournoux (1988) to determine within which Brodmann's area they fall. This reclassification was done in order to avoid possible inconsistencies between studies due to differences in the sources for Brodmann's area classification. 
dinates from Table 2 are plotted onto a rendering of a standardized brain in Figure 1.

Frontopolar activations were observed as consistently as dorsolateral activations for reasoning tasks. Frontopolar activation was reported in 8 of 10 studies and dorsolateral activation was reported in 7 of the 10 studies. The studies that observed dorsolateral activation during reasoning also observed frontopolar, with two exceptions in which only frontopolar activation was observed (Goel et al., 1997; Osherson et al., 1998). These two studies, however, used rather demanding baseline conditions that required complex sentence comprehension and semantic decisions. These demanding baselines may have involved dorsolateral activation to the same extent as the reasoning tasks.

The two studies that did not find frontopolar activation were Owen, Doyon, et al. (1996) and Ragland et al. (1998). In the study by Owen, Doyon, et al., this may be because the procedure allowed participants to approach the task with a strategy that minimized reasoning or complex planning. The study used the Tower of London task, in which participants are presented with two sets of colored balls, one in the upper half of the screen and one in the lower half. There are three balls in each set, and they are arranged in the manner of pool balls hanging in three pockets. The task requires rearranging the lower set of balls (the initial state) to match the upper set (the goal state). The Tower of London has been administered in neuroimaging studies in two different ways. One way is to require participants to rearrange the lower set by moving the balls on a computer monitor. The second way is to require participants to find the minimum number of moves needed to arrange the lower set and press a button corresponding to this number, without executing the moves themselves. In the study by Owen, Doyon, et al., participants responded in the first way, by executing the moves on the computer monitor. As noted by Baker et al. (1996) and Goel and Grafman (1995), although participants are



Figure 1. Distribution of frontopolar and dorsolateral prefrontal activation sites reported in the neuroimaging studies of reasoning, listed in Table 2. The stereotaxic coordinates are plotted within standardized stereotaxic space. For some studies and conditions, more than one activation peak was reported in a given region, so the number of plotted foci exceeds the number of studies included in the analysis. Tower of London plotted in blue; card sorting plotted in yellow; Raven's Matrices plotted in red; inductive reasoning plotted in green. 
encouraged to plan the entire sequence of moves before executing the first one, this procedure allows for a simple trial-and-error strategy and does not necessarily require considering the entire sequence of moves. In contrast, in the study reported by Baker et al., participants had to report the minimum number of moves needed to rearrange an initial configuration of colored balls into the goal configuration. The latter version of the Tower of London requires that participants plan the entire sequence of moves before executing a single response to indicate the minimum number, and it produced frontopolar activation. Thus, the absence of frontopolar activation in the study reported by Owen, Doyon, et al. may be related to the relatively lower reasoning demands.

The second study not reporting frontopolar activation (Ragland et al., 1998) used the WCST, a task that involves matching a "target" card to one of four "reference" cards on the basis of one of three possible dimensions (number, color, or shape). The task requires participants to determine which one of the possible sorting dimensions is the correct one, something that can be done by considering feedback about their accuracy, given after each response. The correct sorting principle changes in a prescribed way (usually every 10 trials), unbeknown to the participant.

The study by Ragland et al. (1998) is the only study in this analysis (Table 1); it used a resting baseline-a reference task that, as noted by Nagahama et al. (1996), may be inappropriate as a control condition for the WCST. In general, the use of resting baseline for the study of complex cognitive processing may be somewhat problematic because of the difficulty of controlling the participant's mental state. Even though participants are instructed to "rest" during the baseline condition, resting in the sense of disengaging oneself from mental activity is notoriously difficult to maintain. Moreover, if during the reference task participants engage in some form of mental activity similar to the processes of interest occurring during the target task, some of the activation regions of interest may be obscured. As will be discussed later in this article, demonstrating frontopolar activation may be particularly sensitive to the nature of the baseline task.

\section{Mental Processes Related to Frontopolar Activation: Evidence From Reasoning Studies}

The foregoing review of reasoning studies shows that both dorsolateral and frontopolar areas are frequently activated during reasoning, but it does not distinguish between these two areas. This may be because in most cases a highly demanding reasoning task was compared to a much less demanding sensorimotor control task. The areas activated by such comparisons may reflect multiple mental operations, and this would make it difficult to dissociate the contributions of different activated regions. Most reasoning studies, however, provide little evidence about what characterizes frontopolar activation per se.

An exception to this is the Tower of London task, which has been employed to vary task difficulty parametrically (e.g., Baker et al., 1996; Owen, Doyon, et al., 1996), thus allowing analysis of task components. On the basis of such analysis of task components, Baker et al. (1996) proposed that the frontopolar cortex is involved in sequence selection and evaluation. Baker et al. used the Tower of London task and compared one condition consisting of "easy" problems that required only two or three moves for an optimal solution versus another condition consisting of "difficult" problems that required four or five minimum moves. Even though both types of problems involved planning and evaluation of a sequence of moves, the "difficult" problems required considering a longer sequence of moves than the "easy" problems. The difficult problems were found to produce significantly greater right frontopolar activation relative to the easy problems, although bilateral increases in dorsolateral activation were also observed. On the basis of evidence from previous studies, Baker et al. attributed the increases in dorsolateral activation to the increased working memory requirements and proposed that the frontopolar activation was reflecting the increased need for sequence selection and evaluation.

There is also evidence to suggest that the frontopolar cortex may be involved in feedback evaluation. Feedback evaluation is a crucial component of the WCST, and four of the five studies using a card sorting task reported activation in this region (Table 1). Tasks other than the WCST have also provided support for the idea that the frontopolar cortex is involved in feedback evaluation. Elliott, Frith, and Dolan (1997) presented participants with a guessing task on the basis of the formal structure of the Tower of London task and varied whether or not participants received feedback after each response. There was frontopolar activation $(x, y, z=14,58,-4$; BA 10) for the feedback condition relative to the nofeedback condition. No dorsolateral activation was found for this comparison.

Another mental process associated with frontopolar activation is hypothesis generation and evaluation-an important aspect of both card sorting and inductive reasoning tasks. During card sorting, participants have to generate hypotheses as to what is the correct sorting rule, and to evaluate these hypotheses in light of the feedback. Four of the five card sorting tasks in Table 1 revealed frontopolar activation.

Inductive reasoning, on the other hand, is in itself considered a form of hypothesis generation and testing (Goel et al., 1997). It has been studied in both the verbal and the visuospatial domain. Neuroimaging studies of verbal inductive reasoning have operationalized induction as the process of evaluating an argument's plausibility, given certain premises. In this case, a hypothesis about the argument's plausibility would have to be generated and evaluated in light of the information contained in the premises. Inductive reasoning has also been studied through nonverbal tasks, such as the RPM, where the same processes of hypothesis generation and evaluation need to be carried out in the visuospatial instead of the 
verbal domain. Frontopolar activation was observed during performance of the RPM task across two types of problems (Prabhakaran et al., 1997). This further supports the possibility that this cortical region may be involved when hypotheses are being generated or evaluated.

In sum, there are several mental operations that seem to be associated with frontopolar activation, namely sequence selection and evaluation, feedback evaluation, and hypothesis generation and evaluation. These mental operations seem to share a common feature that can be described as evaluation of a self-generated response or plan for action. This can be a self-generated sequence of moves or a plan for it in the Tower of London; a self-generated response according to a sorting category in the WCST, or a self-generated hypothesis as to the plausibility of an argument or the item that should follow next in sequence in the case of inductive reasoning and the RPM test. It is possible therefore that the frontopolar cortex is specifically involved in self-referential evaluation, a process that is critical when nonroutine cognitive strategies have to be generated and selected in the context of novel tasks or activities.

If self-referential evaluation and introspective thought in general are processes that characterize the role of the frontopolar cortex, this cortical region should play an important role not only in reasoning, but also in other cognitive domains requiring introspectively based decisions.

\section{Frontopolar Activations in Tasks Other Than Reasoning}

Apart from reasoning, activation of the frontopolar cortex has been observed in a number of functional imaging studies employing various cognitive paradigms, such as self-ordered tasks (Owen, Evans, et al., 1996; Petrides, Alivisatos, Meyer, \& Evans, 1993), semantic monitoring tasks (MacLeod, Buckner, Miezin, Petersen, \& Raichle, 1998), self-relevant tasks (Stone, Seger, Prabhakaran, Gabrieli, \& Glover, 1998), cognitive branching tasks (Koechlin et al., 1999), and working memory tasks (Cohen et al., 1994; Grasby et al., 1993; Jonides et al., 1997; Rypma, Prabhakaran, Desmond, Glover, \& Gabrieli, 1999; E. E. Smith, Jonides, \& Koeppe, 1996). As a more detailed examination reveals, it is likely that these tasks, under the conditions in which they were presented, involved some form of self-referential evaluation. Selfordered tasks usually involve a sequence of responses, where each response can be executed only after the previously executed responses are taken into consideration. Thus, Petrides et al. (1993) used a task that required participants to say aloud in random order the numbers 1 through 10 without repeating themselves; this produced activation in left frontopolar cortex $(x, y, z=-35,42,22$; BA 10/46). Owen, Evans, and Petrides (1996) used another self-ordered task that produced activation in the right frontopolar cortex $(x, y, z=34,51,6$; BA 10). In this case participants touched 8 or 12 circles in a random sequence until one of them changed color. In each trial participants had to avoid the circles that had changed their color on previous trials. Both tasks seem to require that participants evaluate each response in light of the previous responses that they themselves have previously executed.

Semantic monitoring tasks, on the other hand, should not necessarily require self-referential evaluation. However, the specific task used by MacLeod et al. (1998) required not only classifying individual words according to a prespecified semantic category but also monitoring the frequency of words that belonged to this category and making an estimate of this frequency for each block. When this conjoint semantic monitoring and target frequency estimation condition was compared with a passive word viewing control task, right frontopolar cortex was found to be activated $(x, y, z=25,61,6$; BA 10). In three of the five conditions employed by MacLeod et al., participants had to give a gross estimate (i.e., a percentage) of the target frequency, which makes the task bear a striking resemblance to the previously described inductive reasoning tasks, where a hypothesis about the probability of a statement has to be formulated and evaluated. Indeed, relative frequency is considered to be the principal source of information about probability (Gigerenzer \& Murray, 1987). Therefore, it is possible that the generation and evaluation of a target frequency estimate, rather than semantic classification, was the mental operation responsible for frontopolar cortex activation.

Yet another process, that of cognitive branching, was interpreted as responsible for the bilateral frontopolar activation $(x, y, z=36,66,21$; BA 10 and $x, y, z=-36,57,9$; BA 10) reported by Koechlin et al. (1999). Cognitive branching refers to the process of allocating attentional resources when attention has to be alternated between two concurrently ongoing activities. The cognitive branching condition employed by Koechlin et al., consisted of presenting participants with alternating blocks of uppercase and lowercase letters. As upper- and lowercase blocks alternated, participants had to alternate between two different sets of goals, making a judgment for each presented letter. During a lowercase block, the judgment for the first letter in the block was whether or not it was " $t$," and for subsequent letters in the block whether the current letter and the one presented prior to it were in immediate succession in the word tablet. On the other hand, during an uppercase block, the judgment for the first letter was whether or not it was the same as the last letter in the previously presented uppercase block. For subsequently presented letters in uppercase blocks, the judgment was identical to the one for lowercase blocks - whether or not the two letters were in immediate succession in the word tablet. Thus, in order to perform the task, participants had to keep in mind the first set of goals while acting on the second, after which they had to shift to keeping in mind the second set, while acting on the first, and so forth. It is difficult to precisely analyze the component processes in such a demanding situation, but it is possible that in a sequence where two sets of goals alternate in a regular fashion, such as the one used in this study, keeping track of which set of goals is currently to be followed involves 
considering one's own responses to the block of items immediately preceding the current block. Therefore, it is plausible that the task employed by Koechlin et al. involved internally oriented processes.

Another domain in which tasks have sometimes elicited frontopolar activation is working memory. A task that has been used widely in the working memory literature is the $n$-back task, during which participants are presented with a series of items, each appearing one at a time, followed by the next item in the series. The task is to press a button when the item that is being presented at the moment is the same as the one presented a certain number $(n)$ of items earlier. For instance, in a 1-back task, a button has to be pressed if the item is the same as the one presented immediately prior to it, whereas in a 2-back task, it has to match the item presented before the last previously presented item, and so on. Using the $n$-back task, Jonides et al. (1997) found right frontopolar activation for a 2-back condition $(x, y, z=-42,50,22$; BA 10) and bilateral frontopolar activation in a 3-back condition $(x, y, z=-39,44,18$; BA 10 ; and $x, y, z=37,48,18$; BA 10). Using the same $n$-back task in a 2-back condition, Cohen et al. (1994) observed bilateral frontopolar activation for verbal items such as letters $(x, y, z=-29,38$, 20 ; BA 10/46; and $x, y, z=31,42,22$; BA 10/46), as well as spatial items such as locations $(x, y, z=-26,49,11$; BA 10; and $x, y, z=34,53,10$; BA 10). Similarly, using a 3-back condition, E. E. Smith et al. (1996) found leftlateralized frontopolar activation for both letter items $(x, y, z=-37,55,2 ; \mathrm{BA} 10)$ and location items $(x, y, z=$ $-33,44,20$; BA 10).

Using a different working memory task, Grasby et al. (1993) found bilateral frontopolar activation in a supraspan relative to a subspan condition $(x, y, z=-34,46$, 0 ; BA 10; and $x, y, z=24,52,0$; BA 10). The supraspan condition required the free recall of a list of 15 words immediately after they were presented, whereas the subspan condition involved free recall of lists of five words. Yet another working memory task, based on a simultaneous item-recognition task developed by Sternberg (1966), was used in a study by Rypma et al. (1999) and bilateral frontopolar activation was reported for a 6-letter condition in comparison to a 1-letter condition $(x, y, z=$ $-27,53,1$; BA 10 ; and $x, y, z=25,53,1$; BA 10).

In general, working memory conditions that activate frontopolar cortex involve maintenance of working memory load approaching or exceeding the average short-term memory span: Tasks such as 2- or 3-back, or keeping in mind 15 words or six unrelated letters, are usually considered to be around or above span limit. One possible explanation is that as the number of maintained items approaches or exceeds this limit, there appears a need to strategically organize the process of maintenance. The observed frontopolar activations could be related to this additional process of maintenance organization, which may involve processing of internally generated information (such as particular groupings of the items into chunks). Another possible explanation is that prefrontal cortex activation, including activation of frontopolar cortex, is observed whenever there is an increase in task difficulty. The issue of task difficulty and its relation to frontopolar activation will be discussed in greater detail later in this article.

\section{ROSTROCAUDAL PREFRONTAL CORTEX DIFFERENCES: A HIERARCHICAL DISTINCTION}

There is evidence that the dorsolateral prefrontal cortex is specifically involved during the processes of manipulation and monitoring of information within working memory. It represents the second stage of processing in the two-stage model of working memory proposed by Petrides (1994, 1995) and Owen, Evans, and Petrides (1996). This model is based on a hierarchical notion and it contrasts the dorsolateral to the ventrolateral prefrontal cortex. It holds that while only the ventrolateral region is needed for active retrieval and reproduction of one, or a few, pieces of stored information, both the ventrolateral and the dorsolateral regions are needed when monitoring or manipulation of information within working memory is required (Owen, 1997; Owen, Evans, \& Petrides, 1996; Owen et al., 1999). Such a distinction between the processes of maintenance, on the one hand, and the additional processes of manipulation and monitoring, on the other hand, is also evident in a recent review of neuroimaging studies of verbal and spatial working memory by D'Esposito et al. (1998).

However, many tasks involving manipulation and monitoring have been shown to produce activation not only in the dorsolateral but also in the frontopolar cortex. This suggests that the frontopolar cortex may also be involved during these processes. It is, however, possible that these two areas of the cortex are involved in different types of manipulation and monitoring. The type of monitoring and manipulation within working memory associated with dorsolateral prefrontal cortex activation has, in the majority of working memory studies, involved monitoring and manipulation of externally generated information, such as letters or locations. On the other hand, the evidence that the frontopolar cortex is specifically involved in the process of evaluation of self-generated responses or plans for action suggests that the frontopolar cortex may be needed in addition to the dorsolateral when the task requires monitoring and manipulation of information that has been internally generated. In this sense, the frontopolar region can be viewed as subserving an additional, third level of executive processing within the human prefrontal cortex (Figure 2). Therefore, we hypothesize a rostrocaudal distinction within the prefrontal cortex, involving the dorsolateral and frontopolar prefrontal regions, and distinguishing between active processing performed on information that has been externally generated versus processing performed on information that has been self-generated (Figure 2, Stages II and III). This distinction is hierarchical in both anatomical and functional terms: 

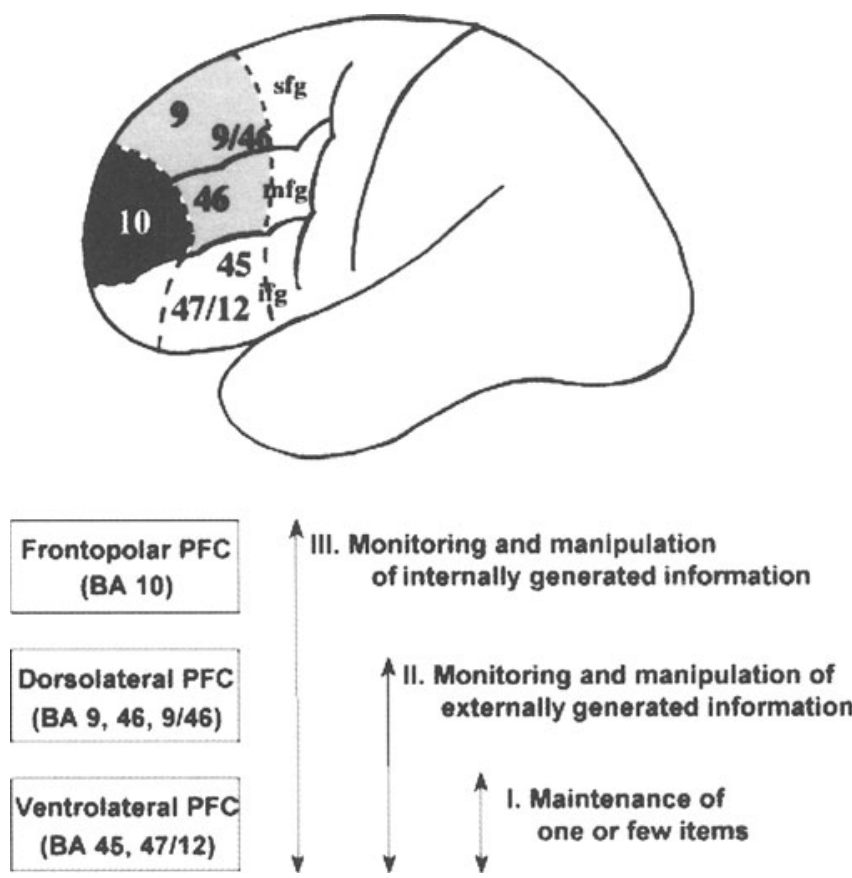

Figure 2. Hierarchical organization of prefrontal function: A threestage model. The top half of the figure presents a schematic drawing of the lateral surface of the human brain and indicates the location of the frontopolar cortex (the lateral surface of area 10), the dorsolateral prefrontal cortex (areas 9,46 , and 9/46), and the ventrolateral prefrontal cortex (areas 45 , and 47/12). The locations of the dorsolateral and ventrolateral regions are in accordance with those proposed by Petrides and Pandya (1994). The bottom half of the figure illustrates the proposed hierarchy of processing stages. The different stages are marked by Roman numerals and the arrows indicate the prefrontal regions proposed to be involved in the corresponding stage. This three-stage model can be regarded as an extension of the two-stage model of prefrontal function proposed by Petrides (1994, 1995) and Owen, Evans, and Petrides (1996). BA, Brodmann's area; PFC, prefrontal cortex; ifg, inferior frontal gyrus; mfg, middle frontal gyrus; sfg, superior frontal gyrus.

The dorsolateral prefrontal cortex may be sufficient for the processing of externally generated information, but both frontopolar and dorsolateral cortex are needed when self-generated information is being processed.

\section{Distribution Analysis of Neuroimaging Studies of Episodic Retrieval}

In an attempt to examine the generality of rostrocaudal prefrontal cortex differences, we next turn to functional neuroimaging results reported in episodic memory retrieval. Episodic retrieval studies have revealed consistent activations in both frontopolar and dorsolateral prefrontal cortex, but they have failed to discover what distinguishes activations in these two prefrontal regions (Henson, Shallice, \& Dolan, 1999; Wagner, Desmond, Glover, \& Gabrieli, 1998). Nonetheless, the frontopolar and the dorsolateral cortex may subserve distinct functions during episodic retrieval and there is some evidence as to what these functions may be: Activation in the dor- solateral prefrontal cortex has been found to be specifically associated with monitoring processes during episodic retrieval (Henson et al., 1999; Shallice et al., 1994); the role of the frontopolar cortex has been somewhat more controversial but, importantly, one of the leading hypotheses has been that it is associated with a postretrieval evaluation of the self-generated products of the retrieval process (Johnson, Kounios, \& Nolde, 1996; Shallice et al., 1994).

Types of episodic retrieval tests. The studies in the following review were classified according to the type of episodic retrieval procedure they used. Episodic retrieval tests can be divided into two groups according to the degree to which the memory judgment requires evaluation of self-generated information. We expected that, on the average, tests in which participants have to evaluate selfgenerated information would be more likely to have resulted in frontopolar activation than when no such introspectively directed evaluation was required. 
Tests classified as requiring minimal evaluation of selfgenerated information included simple episodic recognition procedures, either forced-choice or yes-no recognition. Forced-choice recognition involves indicating which one of two simultaneously presented items (one old and one new) has been previously presented during the acquisition phase; yes-no recognition involves sequential categorization of individual test items as either old or new. In both cases, successful performance on recognition tests is based on evaluating externally generated informationwhether an item has been presented previously or not. It should be noted, however, that even though evaluating self-generated information was not required by the tasks in this group, the possibility that it can occasionally occur cannot be excluded. Indeed, this possibility is especially marked in the sequential yes-no recognition procedure, which may involve setting a criterion for evaluating memory characteristics evoked by test items, which would in its own turn require retrieval and evaluation of previous self-generated responses (Nolde et al., 1998). However, regardless of the possibility that it can occasionally occur, the evaluation of self-generated information is minimally required by these test procedures.

On the other hand, tests classified as requiring more evaluation of self-generated information included cued recall, free recall, and complex recognition procedures such as counting of oddball items within a block. None of these tests can be performed by evaluating externally generated information. In all cases, people must evaluate the information they have self-generated (or retrieved) in response to some sort of cue or instruction. Cued recall typically involves not only the generation but also the evaluation of self-generated answers (Nolde et al., 1998). During cued recall, participants are presented with cues to help them remember specific items learned during acquisition. According to the type of cued recall used, these cues can be word stems, word fragments, or one of a pair of associated words (word associates). Participants need to recall the acquisition word with which the stem or fragment can be completed, or which was associated with the word presented as a cue. Typically, each of the cues can be associated with not only studied but also nonstudied words, and therefore participants may generate more than one solution before attributing one to the acquisition task (Nolde et al., 1998). Thus, cued recall appears to require evaluation of information generated by the participants themselves. Similarly, free recall tasks are generally thought to require self-initiated cuing and selection among possible candidate responses, and would also be likely to involve evaluation of self-generated information. Counting the number of oddball items within a block, on the other hand, even though formally classified as a recognition procedure, presents participants with the dual task of having to categorize each item and keep track of the number of items in the oddball category. This type of procedure most likely requires some complex cognitive processes similar to those previously discussed for cognitive branching and probability estimation, and is therefore likely to involve evaluation of self-generated information.

The studies included in each of the two groups are listed in Table 3. The local maxima of activation reported by the studies are listed in Table 4 and are plotted onto a rendering of a standardized brain in Figure 3 . The studies were divided into two groups: (1) those that used tests requiring evaluation of externally generated information and (2) those that used tests requiring evaluation of internally generated information.

While only half of the recognition studies ( 5 out of 10 ) reported frontopolar activation, nearly all of the other studies ( 13 out of 15 ) reported significant activation foci in this region of the cortex. This difference was statistically significant $\left[\chi^{2}(1, N=25)=4.001, p<.05\right]$. Seven of the 10 recognition studies and 11 of the other 15 studies revealed dorsolateral activation.

To test the difference between the two groups of foci, a multivariate statistical test using Hotelling's $T^{2}$ statistic was employed, comparing the foci in the $x, y$, and $z$ dimensions. The two groups differed significantly in distribution, and this difference held in both hemispheres: $T^{2}=10.84[F(2,11)=4.97, p<.05]$ in the left hemisphere and $T^{2}=7.60[F(2,32)=3.69, p<.05]$ in the right hemisphere. These results suggest a hierarchical distinction between the dorsolateral and the frontopolar cortex: The dorsolateral cortex appears to be involved in both types of evaluative processes, whereas the frontopolar cortex is activated much more consistently by tasks requiring evaluation of self-generated information.

From the five studies that observed frontopolar activation in the group requiring minimal evaluation of selfgenerated information, four used a sequential yes-no recognition procedure (Buckner, Koutstaal, Schacter, Wagner, \& Rosen, 1998; Rugg, Fletcher, Frith, Frackowiak, \& Dolan, 1996, 1997; Wagner et al., 1998). This procedure can sometimes, although not necessarily, involve selfevaluative processes related to criterion setting. In addition, two of these four studies (Rugg et al., 1997; Wagner et al., 1998) employed an encoding manipulation ("deep" vs. "shallow") that may have further contributed to increased self-evaluative demands. The encoding manipulation aimed at varying the probability that studied items would be remembered. The "shallow" encoding condition employed a superficial encoding task, thus creating conditions of increased uncertainty and, possibly, the need for response evaluation. Indeed, Rugg et al. (1997) observed frontopolar activation for the episodic recognition of the words from the "shallow" encoding condition only, and not for the ones from the "deep" encoding condition.

On the other hand, 13 of the 15 studies using tests classified as requiring the evaluation of self-generated information reported frontopolar activation. Two studies did not observe frontopolar activation (Fletcher, Shallice, Frith, Frackowiak, \& Dolan, 1998; Petrides, Alivisatos, \& Evans, 1995). In both cases the procedure used was cued recall of paired associates. In one of the studies, 
Table 3

Episodic Memory Retrieval and Rostrocaudal Prefrontal Cortex Differences

\begin{tabular}{|c|c|c|c|c|c|}
\hline Task & Study & Target Task & Reference Task & Frontopolar (BA10) & Dorsolateral (BA9/46) \\
\hline \multicolumn{6}{|c|}{ Test Requiring Evaluation of Externally Generated Information } \\
\hline \multicolumn{6}{|l|}{ Recognition } \\
\hline \multirow[t]{2}{*}{ Forced Choice } & Moscovitch et al., 1995 & $\begin{array}{l}\text { Object and spatial } \\
\text { recognition }\end{array}$ & Perceptual matching & 一 & $\mathbf{R}$ \\
\hline & Haxby et al., 1996 & Face recognition & Face matching & $\mathbf{R}$ & - \\
\hline \multirow[t]{9}{*}{ Yes-No } & Andreasen et al., 1995 & Word recognition & Word reading & - & $\mathbf{R}$ \\
\hline & Buckner et al., 1998 & Word recognition & Fixation & $\mathbf{R}$ & $\mathbf{B}$ \\
\hline & Nyberg et al., 1995 & Word recognition & Word reading & - & - \\
\hline & Rugg et al., 1996 & Word recognition & $\begin{array}{l}\text { "XXX" and "OOO" } \\
\text { discrimination }\end{array}$ & B & $\mathbf{R}$ \\
\hline & Rugg et al., 1997 & Word recognition & Semantic judgment & $\mathbf{R}$ & B \\
\hline & Rugg et al., 1998 & Word recognition & Word reading & - & - \\
\hline & Wagner et al., 1998 & $\begin{array}{l}\text { Word recognition } \\
\text { (zero density) }\end{array}$ & Word reading & $\mathbf{B}$ & $\mathbf{R}$ \\
\hline & Henson et al., 1999 & Word recognition & $\begin{array}{l}\text { "WORD1" and "WORD2" } \\
\text { discrimination }\end{array}$ & - & B \\
\hline & \multicolumn{4}{|c|}{ Tests Requiring Evaluation of Internally Generated Information } & \\
\hline \multirow{6}{*}{$\begin{array}{l}\text { Cued Recall } \\
\text { Stem or Fragment } \\
\text { Completion }\end{array}$} & & & & & \\
\hline & Buckner et al., 1995 & Stem completion & Word generation & $\mathbf{R}$ & $\mathbf{R}$ \\
\hline & Blaxton et al., 1996 & $\begin{array}{l}\text { Episodic fragment } \\
\text { completion }\end{array}$ & $\begin{array}{l}\text { Semantic fragment } \\
\text { completion }\end{array}$ & B & $\mathbf{R}$ \\
\hline & Bäckman et al., 1997 & Stem completion & Word generation & B & - \\
\hline & Rugg et al., 1998 & $\begin{array}{l}\text { Stem completion } \\
\text { (zero density) }\end{array}$ & Word generation & B & - \\
\hline & $\begin{array}{c}\text { Schacter, Alpert, } \\
\text { et al., } 1996\end{array}$ & Stem completion & Word generation & B & $\mathbf{R}$ \\
\hline \multirow[t]{5}{*}{ Paired Associates } & Fletcher et al., 1995 & $\begin{array}{l}\text { Cued recall of } \\
\text { paired associates }\end{array}$ & $\begin{array}{l}\text { Semantic word } \\
\text { generation }\end{array}$ & $\mathbf{R}$ & - \\
\hline & Petrides et al., 1995 & $\begin{array}{l}\text { Cued recall of } \\
\text { paired associates }\end{array}$ & Word repetition & - & $\mathbf{R}$ \\
\hline & Blaxton et al., 1996 & $\begin{array}{l}\text { Cued recall of } \\
\text { paired associates }\end{array}$ & $\begin{array}{l}\text { Semantic word } \\
\text { generation }\end{array}$ & B & B \\
\hline & Buckner et al., 1996 & $\begin{array}{l}\text { Cued recall of } \\
\text { paired associates }\end{array}$ & Word repetition & $\mathbf{R}$ & $\mathbf{R}$ \\
\hline & Fletcher et al., 1998 & $\begin{array}{l}\text { Cued recall of } \\
\text { paired associates }\end{array}$ & Word repetition & - & $\mathbf{R}$ \\
\hline \multirow{2}{*}{$\begin{array}{l}\text { Free Recall } \\
\quad \text { (Items or Episodic) }\end{array}$} & Petrides et al., 1995 & Free recall & Word repetition & $\mathrm{L}$ & $\mathbf{R}$ \\
\hline & Fletcher et al., 1998 & Free recall & Word repetition & $\mathbf{R}$ & $\longrightarrow$ \\
\hline \multirow[t]{3}{*}{$\begin{array}{l}\text { Counting Oddballs } \\
\text { (During Recognition) }\end{array}$} & Tulving et al., 1994 & $\begin{array}{l}\text { Count oddball (new) } \\
\text { sentences }\end{array}$ & $\begin{array}{l}\text { Count oddball (old) } \\
\text { sentences }\end{array}$ & $\mathbf{R}$ & $\mathbf{R}$ \\
\hline & Tulving et al., 1996 & $\begin{array}{l}\text { Count oddball (new) } \\
\text { sentences }\end{array}$ & $\begin{array}{l}\text { Count oddball (old) } \\
\text { sentences }\end{array}$ & B & B \\
\hline & Wagner et al., 1998 & $\begin{array}{l}\text { Respond to oddball } \\
\text { (new) words }\end{array}$ & $\begin{array}{l}\text { Respond to oddball } \\
\text { (old) words }\end{array}$ & $\mathbf{R}$ & $\mathbf{R}$ \\
\hline
\end{tabular}

Note-B, bilateral; $R$, right; $L$, left. Frontopolar and dorsolateral activations reported by neuroimaging studies (PET and fMRI) of episodic memory retrieval. Only studies reporting stereotaxic coordinates are included. Dashes indicate that no activation was observed in the corresponding region. The tasks requiring evaluation of externally presented information only (top half of table) are proposed to activate only the dorsolateral prefrontal cortex, whereas the tasks requiring (in addition) evaluation of self-generated information (bottom half) are proposed to activate both the frontopolar and the dorsolateral prefrontal cortex. Studies that reported two or more experiments using different episodic retrieval tests (e.g., Fletcher et al., 1998) are listed in each of the task categories, accordingly. Studies that used the same type of retrieval test but varied material type or encoding conditions (e.g., Moscovitch et al., 1995; Rugg et al., 1997; Wagner et al., 1998) are listed only once, in the appropriate task category, after collapsing across the different conditions. The study by Cabeza et al., (1997) is not included because the reference task involved episodic memory encoding. The study by Kapur et al. (1995) is not included because the episodic memory condition involved not only retrieval but also encoding operations. In those cases where the same data were reported more than once, the most complete report is referenced.

Petrides et al. (1995), only five pairs of paired associates were used and they were rehearsed during the learning phase until participants achieved $100 \%$ accuracy. Thus, the episodic retrieval was automatized and the need for selection among different response alternatives, along with the need for evaluation of self-generated information, may have been minimal.

\section{DISCUSSION}

The review of reasoning, episodic retrieval, and other studies presented here provides evidence that the frontopolar cortex may be specifically involved in complex cognitive activities that require evaluation of self-generated information. Frontopolar cortex is nearly ubiquitously 
Table 4

Stereotaxic Coordinates of the Local Maxima of Activation During Episodic Retrieval

\begin{tabular}{|c|c|c|c|c|c|c|c|c|c|c|c|c|c|c|c|c|}
\hline \multirow[b]{3}{*}{ Task/Study } & \multicolumn{8}{|c|}{ Frontopolar Prefrontal Cortex (BA 10) } & \multicolumn{8}{|c|}{ Dorsolateral Prefrontal Cortex (BA 9, BA 46) } \\
\hline & \multicolumn{4}{|c|}{ Left Hemisphere } & \multicolumn{4}{|c|}{ Right Hemisphere } & \multicolumn{4}{|c|}{ Left Hemisphere } & \multicolumn{4}{|c|}{ Right Hemisphere } \\
\hline & $x$ & $\bar{y}$ & $z$ & Area & $x$ & $y$ & $z$ & Area & $x$ & $y$ & $z$ & Area & $x$ & $y$ & $z$ & Area \\
\hline
\end{tabular}

Recognition

Forced Choice

Moscovitch et al., 1995

Haxby et al., 1996

Yes-No

Andreasen et al., 1995

Buckner et al., 1998

Nyberg et al., 1995

Rugg et al., 1996

Rugg et al., 1997

Rugg et al., 1998

Wagner et al., 1998

Henson et al., 1999

Tests Requiring Evaluation of Externally Generated Information

Cued recall

Stem or Fragment Completetion

Buckner et al., 1995

Blaxton et al., 1996

Bäckman et al., 1997

Rugg et al., 1998

Schacter, Alpert, et al., 1996

Paired Associates

Fletcher et al., 1995

Petrides et al., 1995

Blaxton et al., 1996

Buckner et al., 1996

Fletcher et al., 1998

Free recall

Petrides et al., 1995

Fletcher et al., 1998

Counting Oddballs (During Recognition)

Tulving et al., 1994

Tulving et al., 1996

Wagner et al., 1998

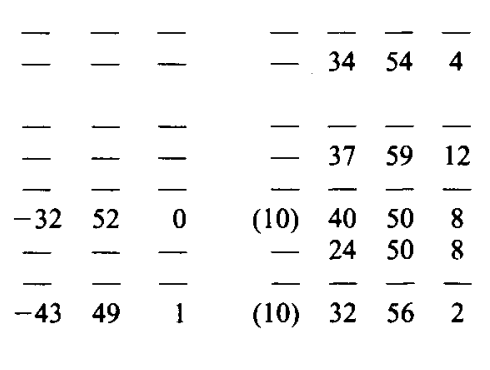

(10) - - -

- $40 \quad 24 \quad 24$

$(9 / 46)$

- $-\overline{50}-$

- $3044 \quad 10$

(10) $\quad-50 \quad 22 \quad 34$

(9) $46 \quad 34 \quad 31$

(10) - - -

$\begin{array}{llll}(10) & -42 & 28 & 32\end{array}$

- - - -

$\begin{array}{llll}- & 38 & 40 & 20 \\ \text { (9) } & 42 & 36 & 28\end{array}$

(9) $42 \quad 36 \quad 28$

(10) - - -

$46 \quad 35 \quad 19$
$-\quad 19$

$(9 / 46)$

(46)

$(9 / 46)$

- - -

- - - -

$-51 \quad 24 \quad 30$

(9) $48 \quad 27 \quad 24$

Tests Requiring Evaluation of Internally Generated Information

\begin{tabular}{|c|c|c|c|c|c|c|c|c|c|c|c|c|c|c|c|}
\hline - & - & - & - & 32 & 50 & 6 & (10) & - & - & - & - & 30 & 29 & 34 & (9) \\
\hline 18 & 56 & 16 & (10) & 22 & 52 & 0 & (10) & - & - & - & - & 36 & 22 & 24 & (46) \\
\hline 38 & 58 & -4 & (10) & 37 & 64 & -9 & (10) & - & - & - & - & - & - & - & - \\
\hline 22 & 46 & 10 & (10) & 36 & 50 & 4 & (10) & - & - & - & - & - & - & - & - \\
\hline-35 & 54 & 8 & (10) & 30 & 46 & 8 & (10) & - & - & - & - & 12 & 47 & 28 & (9) \\
\hline- & - & - & - & 30 & 42 & 24 & (10) & - & - & - & - & - & - & - & - \\
\hline- & - & - & 一 & - & - & - & - & - & - & - & - & 48 & 30 & 35 & (9) \\
\hline 30 & 58 & 4 & (10) & 22 & 58 & 0 & (10) & -36 & 30 & 32 & (9) & 38 & 30 & 32 & (9) \\
\hline - & - & - & - & 29 & 47 & 14 & (10) & - & - & - & - & 41 & 21 & 26 & $(9 / 46)$ \\
\hline - & - & - & - & - & - & - & - & 一 & - & - & - & 38 & 38 & 24 & $(9 / 46)$ \\
\hline-40 & 49 & 26 & $(10 / 46)$ & - & - & - & - & - & - & - & - & 43 & 32 & 38 & (9) \\
\hline & - & - & - & 36 & 44 & 24 & $(10 / 46)$ & - & - & - & - & - & - & - & - \\
\hline 一 & - & - & - & 30 & 50 & 0 & (10) & - & - & - & - & 32 & 44 & 12 & $(46)$ \\
\hline & 52 & 8 & (10) & 22 & 52 & 20 & (10) & -38 & 24 & 28 & $(9 / 46)$ & 32 & 36 & 16 & $(46)$ \\
\hline - & - & - & - & 20 & 63 & -9 & (10) & - & - & - & - & 37 & 35 & 35 & (9) \\
\hline
\end{tabular}

Note-The details of this table are the same as those for Table 3. For studies that reported more than one activation site within the same region, a representative location for this area was selected. The originally reported stereotaxic coordinates were reclassified in the coordinate system of Talairach and Tournoux (1988) to determine within which Brodmann's area they fall. This reclassification was done in order to avoid possible inconsistencies between studies due to differences in the sources for Brodmann's area classification.

activated by complex reasoning tasks, and the few exceptions may be interpreted in terms of specific experimental details. All complex reasoning tasks demand the evaluation of self-generated information. The review of episodic retrieval studies suggested that retrieval tests that require only evaluation of externally generated information are not likely to activate the frontopolar cortex, whereas tasks that pose an additional requirement for evaluation of self-generated information almost invariably produce activation in this region. This provides evidence for a hierarchical distinction between the frontopolar region and the more posteriorly located dorsolateral prefrontal cortex. Both types of evaluation are likely to produce dorsolateral prefrontal cortex activation. Therefore, the proposed rostrocaudal prefrontal cortex distinction should not be taken to imply a double dissociation. Instead, it should be taken to suggest a hierarchical organization in which the frontopolar cortex is necessary, although not sufficient, in order for the most complex stages of processing to be carried out (Figure 2). Thus, not only the frontopolar cortex but also the dorsolateral (and probably other posterior regions) would be needed for the evaluation of self-generated information. Such hierarchical models of information processing are common in sensory and motor systems. Here, we propose such a hierarchical model for prefrontal mediation of thought.

\section{Lesion Studies and Deficits \\ in Self-Referential Evaluation}

Patients with frontal lobe lesions are often impaired on the tasks discussed above as involving self-referential evaluation. Thus, frontal lobe patients exhibit deficits on 


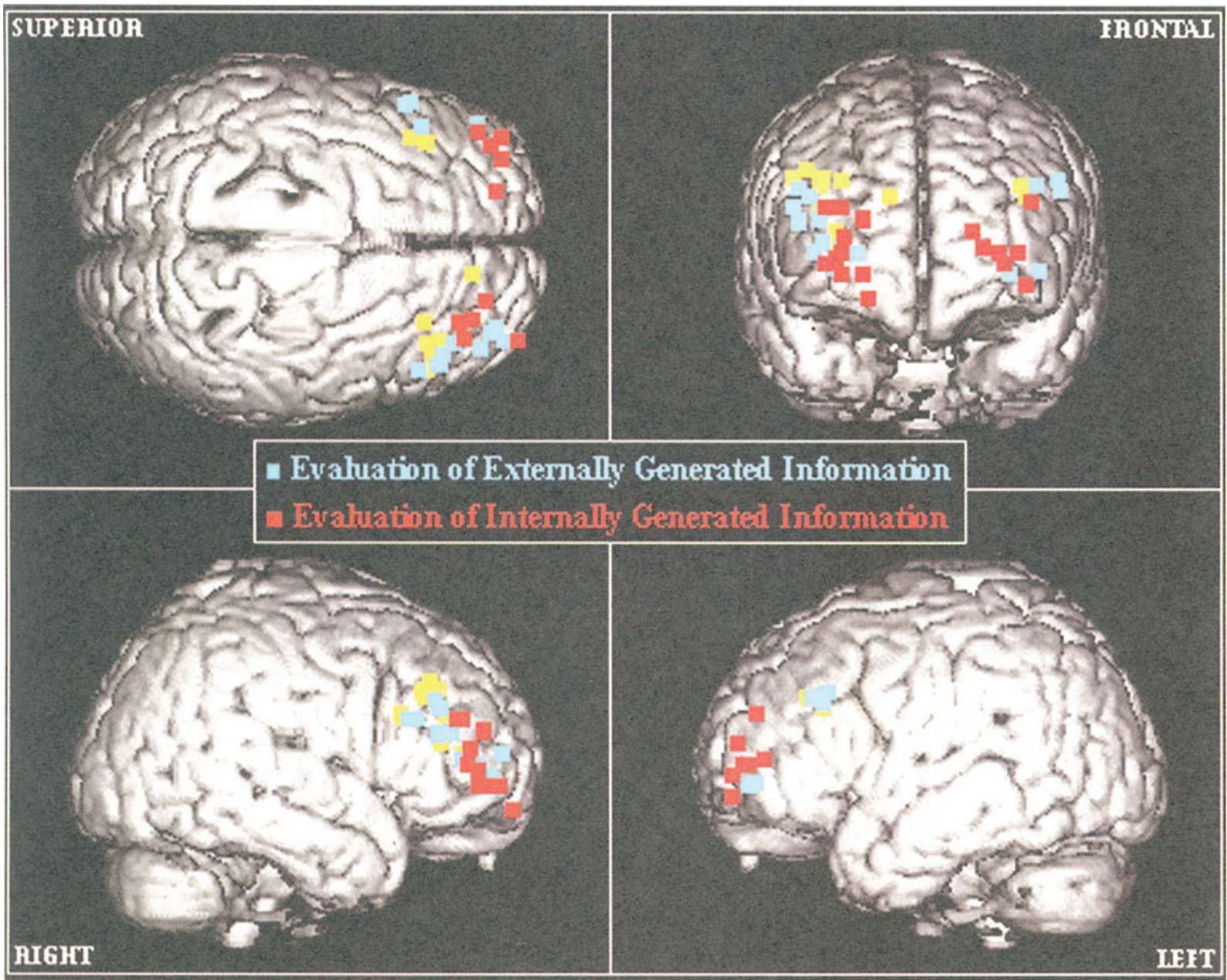

Figure 3. Distribution of frontopolar and dorsolateral prefrontal activation sites reported in the neuroimaging studies of episodic memory retrieval, listed in Table 4. The stereotaxic coordinates are plotted within standardized stereotaxic space. The dorsolateral and frontopolar activation sites reported by studies classified as requiring evaluation of externally generated information are plotted in blue. The frontopolar activation sites reported by studies classified as requiring evaluation of internally generated information are plotted in red; the dorsolateral activation sites reported in this group are plotted in yellow.

all of the previously reviewed reasoning tasks, including the Tower of London (Norman \& Shallice, 1986; Owen, Downes, Sahakian, Polkey, \& Robbins, 1990; Shallice, 1982), the WCST (Milner, 1963, 1964; Robinson, Heaton, Lehman, \& Stilson, 1980), and inductive inference tasks such as judging frequencies (Milner, Petrides, \& Smith, 1985; M L. Smith \& Milner, 1988) and cognitive estimation (Shallice \& Evans, 1978; Vilkki \& Holst, 1991). Importantly, these studies have included frontal lesions that in many cases involved the frontopolar area. Other findings suggesting impaired self-evaluation after frontal lobe damage abound, including the lack of behavioral restraint frequently observed after frontal lobe damage (Miller, 1985), increased impulsivity (Miller, 1992), utilization behavior (Shallice, Burgess, Schon, \& Baxter, 1989), and inability to monitor the effectiveness of selfgenerated plans (Luria, 1973). All of these different im- pairments can be attributed to a general deficit in evaluating self-generated information.

In addition to reasoning, frontal lobe pathology seems to be associated with a specific pattern of memory dysfunction. Importantly, there is impairment in memory performance on free recall tests (della Rocchetta, 1986; Janowsky, Shimamura, \& Squire, 1989; Jetter, Poser, Freeman, \& Markowitsch, 1986), although when the same material is tested in recognition procedures, performance is relatively preserved (e.g., Stuss, Eskes, \& Foster, 1994; for review, see Wheeler, Stuss, \& Tulving, 1995). Free recall was classified above as likely to require evaluation of self-generated retrieval strategies and retrieval outcomes. Consistent with this, the deficit on free recall in frontal lobe patients is generally interpreted as impairment in the subjective organization that aids recall (Gershberg \& Shimamura, 1995). One instantiation of this free 
recall impairment is the frequently observed confabulation and faulty retrieval of remote memories in patients with frontal lobe damage (Baddeley \& Wilson, 1986; Moscovitch, 1989; Stuss, Alexander, Lieberman, \& Levine, 1978; Stuss \& Benson, 1986). Confabulation is also interpreted as a deficit in retrieval strategy and the evaluation of the search outcome (Baddeley \& Wilson, 1986, 1988; Burgess \& Shallice, 1996; Moscovitch, 1989; Squire $\&$ Cohen, 1982). In addition, the performance of prefrontal patients is also impaired on the previously discussed self-ordered working memory tasks (Milner et al., 1985; Petrides \& Milner, 1982), for which the ability to generate and evaluate self-generated strategies is critical.

In addition, frontal lobe patients exhibit a specific and limited deficit on some particular episodic memory tests such as source memory (Janowsky et al., 1989) and recency judgments (Milner, Corsi, \& Leonard, 1991) where, similarly to free recall, self-generated memories must be evaluated, manipulated, or transformed. Patients with frontal lobe lesions also exhibit a propensity to make false alarms or, in other words, to endorse foil or baseline items as having been seen before (Schacter, Curran, Galluccio, Milberg, \& Bates, 1996). This may be related to the previously mentioned processes of criterion setting and could be interpreted as a failure to evaluate and adjust the self-generated criterion used to distinguish between studied items and other items that bear similarity to the studied items.

Unfortunately, in the majority of clinical cases there is a lack of detailed knowledge about the lesions, and even when their extent is known, it rarely follows precisely functional or architectonic borders. This, in addition to the need to average across patients with sometimes very different lesion locations, can greatly reduce the ability to make subregional inferences. However, at least one lesion study has provided evidence consistent with the rostrocaudal prefrontal distinction proposed here. Vilkki and Holst (1991) used a digit symbol test to assess the ability to achieve a self-selected goal defined as the number of symbols the patients estimated would be achieved in 1 min or less. Patients with anterior prefrontal lesions were found to be more impaired than patients with posterior prefrontal lesions in estimating achievable goals-a process relying extensively on self-referential evaluation.

\section{Relation Between Neuroimaging and Patient Findings}

The following parallel can be drawn between the brain lesion and functional neuroimaging results discussed so far: Patients with prefrontal lesions appear to be impaired on tasks, such as free recall, that are usually associated with frontopolar activation (in addition to dorsolateral). On the other hand, they exhibit only mild or no impairment on tasks such as recognition, which tend to produce dorsolateral (but no frontopolar) activation in healthy controls. This may at first appear somewhat surprising because it seems as if the dorsolateral cortex is not necessary for performance in neuropsychological studies of brain-lesioned patients, even though it is consistently recruited by the same tasks in neuroimaging studies of healthy people. In principle, there is a possibility that at least some of the activation observed in neuroimaging studies is epiphenomenal and that damage to a consistently activated region may have little or no effect on performance. There are, however, at least two other possible explanations, consistent with a hierarchical rostrocaudal prefrontal organization. First, for statistical reasons, a group of mixed prefrontal lesions is likely to include more patients with lesions in either one of these two regions than patients with lesions in only one of themthe dorsolateral. For tasks requiring both regions, lesions extending over either one of the two regions would produce deficits, whereas for tasks requiring only dorsolateral cortex, only a subset of these lesions - the ones extending over the dorsolateral region-would produce deficits. Therefore, on the average, the group would show a stronger deficit for tasks requiring both regions than for tasks requiring only dorsolateral cortex.

This alone, however, may not be sufficient to account for the normal performance of prefrontal groups on tasks that involve dorsolateral activation. In view of the hierarchical relationship between the two regions, it is conceivable that task processes usually associated specifically with dorsolateral prefrontal cortex activation may also be subserved by the frontopolar cortex, which, although normally not recruited, may take over some of the functions of the dorsolateral prefrontal cortex when the latter is lesioned. In such a case, only the patients with lesions extending over both the dorsolateral and the frontopolar cortex would be impaired, which would greatly reduce the probability that the group on the average will exhibit a deficit. However, whether the frontopolar cortex in patients with dorsolateral lesions can indeed assume functions typically subserved by the dorsolateral cortex remains to be determined by future neuroimaging studies of patient populations. In any case, it is striking that the deficits seen in patients with frontal lesions are more closely linked to frontopolar than dorsolateral activations in healthy people.

\section{Demonstrating Frontopolar Activation: Some Methodological Issues}

Detectability of frontopolar activation. There are several issues related to the ability to detect frontopolar cortex activation using functional neuroimaging techniques such as position emission tomography (PET) and functional magnetic resonance imaging (fMRI). One issue, specific to the fMRI method of signal registration, is the use of a surface headcoil positioned around the participant's head. Different headcoils can vary in the extent to which they cover the head surface in an anterior direction. Because only a full coverage of the anterior-most part of the head would allow reliable detection of frontopolar signal, the use of headcoils that do not completely cover the full extent of the head may substantially reduce the ability to detect frontopolar activation in some stud- 
ies. In addition, the blood oxygenation level-dependent (BOLD) signal measured by fMRI techniques can be severely altered by macroscopic susceptibility artifacts arising at brain tissue boundaries. Such artifacts can attenuate the activation signal, leading to "blind spots" in some regions of brain adjacent to bone and air sinuses (Ojemann et al., 1997). This effect can produce a significant artifact in prefrontal cortex because of the susceptibility differences between the ethmoidal air cells and brain tissue, resulting in partial or complete signal extinction from the orbitofrontal cortex and the frontal poles. Signal loss, its extent, and the associated geometric distortions can be influenced by slice orientation and the chosen phase-encode direction (Mottaghy et al., 1999). Such artifacts are especially pronounced when axial slice orientation and echo-planar imaging are employed (Ojemann et al., 1997) and may reduce the ability to reliably detect frontopolar activation.

Another issue, common to both PET and fMRI, is the regional variability of signal intensity. It is known that there are differences in oxidative metabolism and regional microvascular anatomy between different brain regions (see, e.g., Lierse, 1963; Perlmutter, Powers, Herscovitch, Fox, \& Raichle, 1987), as well as regional differences in the magnitude of activation-induced BOLD signal (Kastrup, Krüger, Glover, Neumann-Haefelin, \& Moseley, 1999). Although these studies have concentrated on comparing large-scale brain areas, it is possible that there are also differences between subregions within the frontal cortex that are influencing the relative strength of signal. More detailed analyses comparing different prefrontal subregions are needed in order to determine the specific differences in regional vasculature and the influence of such differences on the detectability of signal changes within different prefrontal subregions.

The choice of a baseline condition. Even though technical issues related to signal registration undoubtedly influence the detectability of frontopolar activation, the primary factors responsible for such activation are presumed to be related to the specifics of the experimental procedure. Importantly, the presence or absence of frontopolar activation would be determined not only by the choice of an experimental task, but also by the choice of a baseline condition. As noted, the use of a resting baseline condition for the study of complex cognitive processes can be problematic because it leaves open the possibility that participants engage in some form of mental activity. During a resting baseline condition participants are not exposed to any externally generated information, so it is likely that such mental activity, if it occurs, would be oriented toward the participants' own internal mental states. For instance, participants may evaluate their own performance on the experimental task or engage in some other mental activity performed on information that has been internally generated. Therefore, a resting baseline may be particularly detrimental to demonstrating frontopolar cortex activation because, as suggested by the review of literature here, the frontopolar cortex may be specifically involved in such processes performed on internally generated information.

Indeed, there are several examples from studies reported in the neuroimaging literature that support the view that the frontopolar cortex may be activated by uncontrolled mental processes occurring during rest conditions. Buckner, Raichle, Miezin, and Petersen (1996) used two reference tasks-a word repetition baseline and a resting baseline with eyes open. The target task of cued recall of paired associates yielded right frontopolar activation $(x, y, z=29,47,14$; BA 10$)$ when it was compared with the word repetition baseline but not when it was compared with the resting baseline. Similarly, Buckner, Petersen, Ojemann, Miezin, Squire, and Raichle (1995) observed right frontopolar activation $(x, y, z=32$, 50,6 ; BA 10) during stem completion when it was compared with a word generation baseline, but not when it was compared with a fixation baseline. These findings suggest that frontopolar activation is greater during rest or fixation than during semantic tasks. Presumably, this reflects the greater opportunity for self-referential thought to occur during rest or fixation than during simple test performance.

Moreover, not only resting but sometimes even processing baselines, if not sufficiently engaging, may cause frontopolar activation to be obscured. There are at least two examples from neuroimaging studies where a task of interest showed frontopolar activation relative to a demanding baseline task, but not relative to a less demanding task. One example is a working memory study (Owen et al., 1999) where a comparison of a spatial 2-back condition with a relatively undemanding visuomotor control condition did not yield frontopolar activation, whereas the same 2-back condition compared with a more demanding spatial span task yielded right frontopolar activation $(x, y, z=38,42,20$; BA 10). In another example (Grasby et al., 1993), cued retrieval of paired associates from episodic memory in comparison with semantic word generation produced right frontopolar activation $(x, y, z=$ $30,42,24$; BA 10/46), whereas the same episodic retrieval condition compared with a less demanding word repetition baseline caused the activation locus to be displaced away from the frontopolar cortex toward the medial prefrontal region $(x, y, z=18,28,24$; BA 32).

The examples described here indicate that in order to be able to observe frontopolar activation during a target condition, the baseline should be as carefully chosen as the target condition itself and should be appropriately designed so that it poses sufficient processing demands to discourage participants from engaging in self-oriented mental processes; at the same time, however, it should be designed so that it is not overly demanding either. In general, if the frontopolar cortex, as suggested here, participates in active processing performed on internally generated information, the ability to detect changes of activation in this area may be strongly related to successfully eliminating such self-oriented mental activity during the baseline condition. 


\section{Frontopolar Cortex and the Issue of Task Difficulty}

As mentioned previously, task manipulations that produce frontopolar activation are often associated with increases in difficulty from baseline to experimental condition. This raises the following question: Is it possible that the observed frontopolar activations are due to the increases in task difficulty rather than the specific process proposed here - the evaluation of internally generated information?

There is evidence to suggest that considering only task difficulty is not sufficient to characterize frontopolar activations. One line of evidence comes from the working memory literature, where task difficulty has been identified in terms of working memory load. Increasing the working memory load linearly does not by itself produce linear increases in the frontopolar cortex, as revealed by studies on the effects of load in 0-back, 1-back, 2-back, and 3-back conditions (Braver et al., 1997; Cohen et al., 1997). Neither of these studies reported an effect of the linearly increasing load on the frontopolar cortex, although both found such an effect on the dorsolateral prefrontal cortex. By contrast, Grasby et al. (1994) used an immediate free recall task on word lists varying from 2 to 13 words in length and found significant correlations between list length and regional cerebral blood flow (rCBF) in the frontopolar cortex bilaterally $(x, y, z=-24$, $48,-8$; BA 10 ; and $x, y, z=30,48,4$; BA 10). However, the free recall of lists of words of increasing length most likely involves not only increase in working memory load but also, and perhaps more importantly, increase in the need to strategically organize and monitor and process of recall.

Another line of evidence comes from neuroimaging studies of deductive reasoning, which have shown that frontopolar activation can also be associated with decreasing task difficulty. Although deductive reasoning tasks are more difficult than inductive reasoning tasks according to both accuracy and reaction time measures (Evans, Newstead, \& Byrne, 1993; Goel et al., 1997), the latter activate the frontopolar cortex whereas the former do not (Goel et al., 1997; Osherson et al., 1998). Even stronger support for this comes from the results reported by Osherson et al., who directly compared inductive with deductive reasoning and observed left frontopolar cortex activation $(x, y, z=-40,48,16$; BA 10/46). This suggests that activation in the frontopolar prefrontal cortex is not driven by increased difficulty per se, but that there may be some additional and qualitatively different component processes in the tasks that recruit this region relative to the ones that only recruit the dorsolateral prefrontal cortex.

In general, explaining prefrontal activations with increased task difficulty may seem attractive, with its apparent parsimony. However, such an explanation posits an implicit theory of prefrontal function. Namely, it assumes the view that the prefrontal cortex is functionally homogeneous and its functions can be reduced to a single unitary concept, in this case, task difficulty. However, reducing prefrontal abilities to any one unitary process does not appear to be compatible with psychological and anatomical data (Stuss et al., 1994). On the basis of behavioral analysis, several authors have argued that frontal functions are multiple, divisible, and fractionated (Fuster, 1980; Shallice \& Burgess, 1991 a, 1991b; Stuss \& Benson, 1986). In addition, tests of prefrontal functions such as the Tower of London and the WCST have been found to measure dissociable aspects of prefrontal function that contribute to task performance above and beyond basic working memory processes (Robbins, 1996). All of this provides evidence that additional factors beyond task difficulty need to be taken into account.

It is nonetheless important to note that there is probably no correct answer to the question of whether the prefrontal cortex is characterized by a heterogeneity or homogeneity of function. At a general level of analysis, it may be possible to describe prefrontal functions by using a single generalized process such as task difficulty. However, when a more specific description of prefrontal function is desired, multiple processes and component subprocesses may have to be considered in order to fully characterize functional differences at the subregional level. Thus, depending on the level of discourse being used, or the level of psychological and anatomical analysis, frontal lobe functions can be described as either homogeneous or heterogeneous (Stuss et al., 1994). Hence, an explanation of frontopolar activation involving general task difficulty does not contradict an explanation involving specific processes such as the evaluation of internally generated information. Rather, these are parallel explanations at two different levels of analysis.

If the cognitive processes subserved by the dorsolateral and frontopolar cortex are organized according to the hierarchical distinction proposed here, then systematic differences in difficulty can be expected between tasks involving only one level of this hierarchy and tasks involving both levels. Tasks requiring processing of internally generated information would involve both hierarchical levels and are likely to be cognitively more complex than tasks requiring processing of externally generated information and involving only one level. Thus, dorsolateral activation would be observed for both types of tasks and frontopolar activation only for the more difficult. We further hypothesize that frontopolar activation reflects specifically the cognitive difficulty of a task, rather than other dimensions of difficulty, such as perceptual or motor. Convincing support for this hypothesis will require experiments that study specifically the evaluation of internally generated information.

\section{CONCLUSIONS}

The review of reasoning and episodic retrieval studies presented here suggests that the frontopolar cortex is a 
functionally distinct prefrontal region that may be selectively involved in active processing, such as evaluation, monitoring or manipulation, performed on internally generated information. It is proposed that there may be a hierarchical distinction in a rostrocaudal direction between the frontopolar and the dorsolateral prefrontal regions of the cortex. Dorsolateral cortex may be sufficient for the evaluation or manipulation of externally generated information, whereas frontopolar cortex is additionally required when evaluation and manipulation of internally generated information needs to be performed. Such a hierarchical distinction is consistent with, and can be viewed as an extension of, the two-stage model of processing within the lateral prefrontal cortex that has been previously proposed in the literature. This latter model has viewed the ventrolateral and dorsolateral regions as subserving two different stages of executive processing within the lateral prefrontal cortex, with the dorsolateral region being involved at the second stage, where monitoring and manipulation of information held in working memory is required. The rostrocaudal prefrontal cortex distinction proposed here goes one step further and suggests that the frontopolar region in the human prefrontal cortex can be seen as subserving a third stage of executive processing, involving evaluation of information that has been generated at the previous stage of executive processing. Thus the ventrolateral, dorsolateral, and frontopolar regions can be seen as forming a three-stage hierarchical system within the prefrontal cortex.

More generally, approaching the prefrontal cortex with the assumption of heterogeneity of function and viewing it as a region subserving multiple and differently localized processes appears to be a beneficial approach toward identifying neurally plausible component processes of complex cognition. In particular, the regional distinction proposed here suggests that self-referential or introspectively oriented mental activity may be qualitatively different from externally oriented mental activity concentrated on externally generated information. In view of the types of functional distinctions that have been proposed to hold within the human prefrontal cortex, it appears that different prefrontal subregions are best distinguished by viewing them as the components of a hierarchically organized system. Consequently, the general principle according to which the prefrontal cortex is organized may be not so much that of regional dissociations as much as that of a hierarchical organization. The challenge to future theories and research of prefrontal function will be to refine and further our knowledge of this organization.

\section{REFERENCES}

Aguirre, G. K., Zarahn, E., \& D’Esposito, M. (1997). Empirical analyses of BOLD fMRI statistics: II. Spatially smoothed data collected under null-hypothesis and experimental conditions. Neurolmage, $\mathbf{5}$, 199-212.

Alexander, G. E., DeLong, M. R., \& Strick, P. L. (1986). Parallel organization of functionally segregated circuits linking basal ganglia and cortex. Annual Review of Neuroscience, 9, 357-381.
Andreasen, N. C., O'Leary, D. S., Arndt, S., Cizadlo, T., Hurtig, R., Rezai, K., Watkins, G. L., Ponto, L. L., \& Hichwa, R. D. (1995). Short-term and long-term verbal memory: A positron emission tomography study. Proceedings of the National Academy of Sciences, 92, 5111-5115.

Bäckman, L., Almkvist, O., Andersson, J., Nordberg, A., WinBLAD, B., REINECK, R., \& LÅNGSTRÖM, B. (1997). Brain activation in young and older adults during implicit and explicit retrieval. Journal of Cognitive Neuroscience, 9, 378-391.

BAdDELEY, A., \& Wilson, B. (1986). Amnesia, autobiographical memory, and confabulation. In D. C. Rubin (Ed.), Autobiographical memory (pp. 225-252). Cambridge: Cambridge University Press.

BadDELEY, A., \& Wilson, B. (1988). Frontal amnesia and the dysexecutive syndrome. Brain \& Cognition, 7, 212-230.

Baker, S. C., Rogers, R. D., OWen, A. M., Frith, C. D., Dolan, R. J., Frackowiak, R. S. J., \& Robbins, T. W. (1996). Neural systems engaged by planning: A PET study of the Tower of London task. Neuropsychologia, 34, 515-526.

Barbas, H., \& PANDYA, D. N. (1991). Patterns of connections of the prefrontal cortex in the rhesus monkey associated with cortical architecture. In H. S. Levin, H. M. Eisenberg, \& A. L. Benton (Eds.), Frontal lobe function and dysfunction (pp. 35-58). New York: Oxford University Press.

Berman, K. F., Ostrem, J. L., Randolph, C., Gold, J., Goldberg, T. E., Coppola, R., Carson, R. E., Herscovitch, P., \& Weinberger, D. R. (1995). Physiological activation of a cortical network during performance of the Wisconsin Card Sorting Test: A positron emission tomography study. Neuropsychologia, 33, 1027-1046.

Blaxton, T. A., Bookheimer, S. Y., ZefFiro, T. A., Figlozzi, C. M., GaILlard, W. D., \& Theodore, W. H. (1996). Functional mapping of human memory using PET: Comparisons of conceptual and perceptual tasks. Canadian Journal of Experimental Psychology, 50, 42-56.

Braver, T. S., Cohen, J. D., Nystrom, L. E., Jonides, J., Smith, E. E., \& NoLL, D. C. (1997). A parametric study of prefrontal cortex involvement in human working memory. Neurolmage, 5, 49-62.

BRoDMANN, K. (1908). Beiträge zur histologischen Lokalisation der Grosshirnrinde. VI Mitteilung. Die Cortexgliederung des Menschen [Writings on the histological localization in the cerebral cortex: Vol. 6. Organization of the human cortex]. Journal of Psychological Neurology, 10, 213-246.

Buckner, R. L., Koutstaal, W., Schacter, D. L., Wagner, A. D., \& Rosen, B. R. (1998). Functional-anatomic study of episodic retrieval using fMRI. I. Retrieval effort versus retrieval success. Neurolmage, 7, 151-162.

Buckner, R. L., Petersen, S. E., Ojemann, J. G., Miezin, F. M., SQUIRE, L. R., \& RAICHLE, M. E. (1995). Functional anatomical studies of explicit and implicit memory retrieval tasks. Journal of Neuroscience, 15, 12-29.

Buckner, R. L., Raichle, M. E., Miezin, F. M., \& Petersen, S. E. (1996). Functional anatomic studies of memory retrieval for auditory words and visual pictures. Journal of Neuroscience, 16, 6219-6235.

Burgess, P. W., \& Shallice, T. (1996). Confabulation and the control of recollection. Memory, 4, 359-411.

Cabeza, R., Kapur, S., Craik, F. I. M., Mcintosh, A. R., Houle, S., \& Tulving, E. (1997). Functional neuroanatomy of recall and recognition: A PET study of episodic memory. Journal of Cognitive Neuroscience, $9,254-265$.

CAmpbell, A. W. (1905). Histological studies on the localization of cerebral function. Cambridge: Cambridge University Press.

Cohen, J. D., Forman, S. D., Braver, T. S., Casey, B. J., ServanSchreiber, D., \& Noll, D. C. (1994). Activation of the prefrontal cortex in a nonspatial working memory task with functional MRI. Human Brain Mapping, 1, 293-304.

Cohen, J. D., Perlstein, W. M., Braver, T. S., Nystrom, L. E., Noll, D. C., JoNIDEs, J., \& SMITH, E. E. (1997). Temporal dynamics of brain activation during a working memory task. Nature, 386, 604-608.

Damasio, A. R. (1996). The somatic marker hypothesis and the possible functions of the prefrontal cortex. Philosophical Transactions of the Royal Society of London: Series B, 351, 1413-1420. 
DELla RoccheTta, A. I. (1986). Classification and recall of pictures after unilateral frontal or temporal lobectomy. Cortex, 22, 189-211.

D'Esposito, M., Aguirre, G. K., Zarahn, E., Ballard, D., Shin, R. K., \& LEASE, J. (1998). Functional MRI studies of spatial and nonspatial working memory. Cognitive Brain Research, 7, 1-13.

Di Pellegrino, G., \& Wise, S. P. (1991). A neurophysiological comparison of three distinct regions of the primate frontal lobe. Brain, 114, 951-978.

Elliott, R., Frith, C. D., \& Dolan, R. J. (1997). Differential neural response to positive and negative feedback in planning and guessing tasks. Neuropsychologia, 35, 1395-1404.

ElliotT SMith, G. (1907). A new topographical survey of the human cerebral cortex. Journal of Anatomy \& Physiology, 41, 237-254.

Evans, J. S. B. T., Newstead, S. E., \& Byrne, R. M. J. (1993). Human reasoning: The psychology of deduction. Hillsdale, NJ: Erlbaum.

Fletcher, P. C., Frith, C. D., Grasby, P. M., Shallice, T., FrackOWIAK, R. S., \& DolAN, R. J. (1995). Brain systems for encoding and retrieval of auditory-verbal memory: An in vivo study in humans. Brain, 118, 401-416.

Fletcher, P. C., Shallice, T., Frith, C. D., Frackowiak, R. S., \& Dolan, R. J. (1998). The functional roles of prefrontal cortex in episodic memory: II. Retrieval. Brain, 121, 1249-1256.

FUSTER, J. M. (1980). The prefrontal cortex: Anatomy, physiology, and neuropsychology of the frontal lobe. New York: Raven.

Gershberg, F. B., \& Shimamura, A. P. (1995). Impaired use of organizational strategies in free recall following frontal lobe damage. Neuropsychologia, 33, 1305-1333.

Gigerenzer, G., \& Murray, D. J. (1987). Cognition as intuitive statistics. Hillsdale, NJ: Erlbaum.

GoEl, V., Gold, B., KaPuR, S., \& Houle, S. (1997). The seats of reason? An imaging study of deductive and inductive reasoning. NeuroReport, 8, 1305-1310.

Goel, V., Gold, B., Kapur, S., \& Houle, S. (1998). Neuroanatomical correlates of human reasoning. Journal of Cognitive Neuroscience, 10, 293-302.

Goel, V., \& Grafman, J. (1995). Are the frontal lobes implicated in "planning" functions? Interpreting data from the Tower of Hanoi. Neuropsychologia, 33, 623-642.

Goldberg, T. E., Berman, K. F., Fleming, K., Ostrem, J., Van Horn, J. D., Esposito, G., MatTay, V. S., Gold, J. M., \& WeinberGer, D. R. (1998). Uncoupling cognitive workload and prefrontal cortical physiology: A PET rCBF study. NeuroImage, 7, 296-303.

GolDMAN-RAKIC, P. S. (1987). Circuitry of primate prefrontal cortex and regulation of behavior by representational memory. In F. Plum \&V. B. Mountcastle (Eds.), Handbook of physiology: Sec. 1. The nervous system: Vol. 5. Higher functions of the brain (pp. 373-417). Bethesda, MD: American Physiological Society.

Grasby, P. M., Frith, C. D., Friston, K. J., Bench, C., Frackowiak, R. S., \& Dolan, R. J. (1993). Functional mapping of brain areas implicated in auditory-verbal memory function. Brain, 116, 1-20.

Grasby, P. M., Frith, C. D., Friston, K. J., Simpson, J., Fletcher, P. C., Frackowiak, R. S., \& Dolan, R. J. (1994). A graded task approach to the functional mapping of brain areas implicated in auditoryverbal memory. Brain, 117, 1271-1282.

HaXby, J. V., Ungerleider, L. G., HorWitz, B., Maisog, J. M., RaPOPORT, S. I., \& GRADY, C. L. (1996). Face encoding and recognition in the human brain. Proceedings of the National Academy of Sciences, 93, 922-927.

Henson, R. N., Shallice, T., \& Dolan, R. J. (1999). Right prefrontal cortex and episodic memory retrieval: A functional MRI test of the monitoring hypothesis. Brain, 122, 1367-1381.

Janowsky, J. S., Shimamura, A. P., \& SQuiRe, L. R. (1989). Source memory impairment in patients with frontal lobe lesions. Neuropsychologia, 27, 1043-1056.

Jetter, W., Poser, U., Freeman, R. B. J., \& Markowitsch, H. J. (1986). A verbal long-term memory deficit in frontal lobe damaged patients. Cortex, 22, 229-242.

Johnson, M. K., Kounios, J., \& NoldE, S. F. (1996). Electrophysiological brain activity and memory source monitoring. NeuroReport, 7, 2929-2932.
Jonides, J., Schumacher, E. H., Smith, E. E., Lauber, E. J., Awh, E., MinOSHIMA, S., \& KoEPPE, R. (1997). Verbal working memory load affects regional brain activation as measured by PET. Journal of Cognitive Neuroscience, 9, 462-475.

Kapur, S., Craik, F. I. M., Jones, C., Brown, G M., Houle, S., \& TulVING, E. (1995). Functional role of the prefrontal cortex in retrieval of memories: A PET Study. NeuroReport, 6, 1880-18884.

Kastrup, A., Krüger, G., Glover, G. H., NeumanN-Haefelin, T., \& MOSELEY, M. E. (1999). Regional variability of cerebral blood oxygenation response to hypercapnia. Neurolmage, 10, 675-681.

Koechlin, E., Basso, G., Pietrini, P., Panzer, S., \& Grafman, J. (1999). The role of the anterior prefrontal cortex in human cognition. Nature, 399, 148-151.

LIERSE, W. (1963). Die Kapillardichte im Wirbeltiergehirn [Density of the capillaries in the vertebrate brain]. Acta Anatomica, 54, 1-31.

LURIA, A. R. (1973). The working brain: An introduction to neuropsychology. New York: Basic Books.

MacLeod, A. K., Buckner, R. L., Miezin, F. M., Petersen, S. E., \& RAICHLE, M.E. (1998). Right anterior prefrontal cortex activation during semantic monitoring and working memory. Neurolmage, 7, 41-48.

Miller, L. A. (1985). Cognitive risk-taking after frontal or temporal lobectomy-I. The synthesis of fragmented visual information. Neuropsychologia, 23, 359-369.

MILLER, L. A. (1992). Impulsivity, risk-taking, and the ability to synthesize fragmented information after frontal lobectomy. Neuropsychologia, 30, 69-79.

MILNER, B. (1963). Effects of different brain lesions on card sorting Archives of Neurology, 9, 90-100.

MiLnER, B. (1964). Some effects of frontal lobectomy in man. In J. M Warren \& K. Akert (Eds.), The frontal granular cortex and behavior (pp. 313-334). New York: McGraw-Hill.

MILNER, B., CORSI, P., \& Leonard, G. (1991). Frontal-lobe contribution to recency judgements. Neuropsychologia, 29, 601-618.

Mizner, B., Petrides, M., \& Smith, M. L. (1985). Frontal lobes and the temporal organization of memory. Human Neurobiology, 4, 137-142.

Moscovitch, M. (1989). Confabulation and the frontal systems: Strategic versus associative retrieval in neuropsychological theories of memory. In H. L. Roediger III \& F. I. M. Craik (Eds.), Varieties of memory and consciousness: Essays in honour of Endel Tulving (pp. 133160). Hillsdale, $\mathrm{NJ}$ : Erlbaum.

Moscovitch, M., KaPur, S., Köhler, S., \& Houle, S. (1995). Distinct neural correlates of visual long-term memory for spatial location and object identity: A positron emission tomography study in humans. Proceedings of the National Academy of Sciences, 92, 3721-3725.

Mottaghy, F. M., Shah, N. J., Krause, B. J., Schmidt, D., HalsBAND, U., JANCKE, L., \& Muller-Gartner, H. (1999). Neuronal correlates of encoding and retrieval in episodic memory during a paired-word association learning task: A functional magnetic resonance imaging study. Experimental Brain Research, 128, 332-342.

Nagahama, Y., Fukuyama, H., Yamauchi, H., Matsuzaki, S., KoNishi, J., Shibasaki, H., \& Kimura, J. (1996). Cerebral activation during performance of a card sorting test. Brain, 119, 1667-1675.

Nolde, S. F., Johnson, M. K., \& Raye, C. L. (1998). The role of prefrontal cortex during tests of episodic memory. Trends in Cognitive Sciences, 2, 399-406.

Norman, D. A., \& Shallice, T. (1986). Attention to action: Willed and automatic control of behavior. In R. J. Davidson, G. E. Schwarts, \& D. Shapiro (Eds.), Consciousness and self-regulation: Advances in research and theory (Vol. 4, pp. 1-18). New York: Plenum.

Nyberg, L., Cabeza, R., \& Tulving, E. (1996). PET studies of encoding and retrieval: The HERA model. Psychonomic Bulletin \& Review, 3, 135-148.

Nyberg, L., Tulving, E., Habib, R., Nilsson, L. G., Kapur, S., Houle, S., CABEZA, R., \& McInTosh, A. R. (1995). Functional brain maps of retrieval mode and recovery of episodic information. NeuroReport, 7, 249-252.

Ojemann, J. G., Akbudak, E., Snyder, A. Z., McKinstry, R. C., Raichle, M. E., \& ContUro, T. E. (1997). Anatomic localization and quantitative analysis of gradient refocused echo-planar fMRI susceptibility artifacts. NeuroImage, 6, 156-167. 
Osherson, D., Perani, D., Cappa, S., Schnur, T., Grassi, F., \& FAzIO, F. (1998). Distinct brain loci in deductive versus probabilistic reasoning. Neuropsychologia, 36, 369-376.

OWEN, A. M. (1997). The functional organization of working memory processes within human lateral frontal cortex: The contribution of functional neuroimaging. European Journal of Neuroscience, 9, 1329-1339.

Owen, A. M., Downes, J. J., Sahakian, B. J., Polkey, C. E., \& RobBINS, T. W. (1990). Planning and spatial working memory following frontal lobe lesions in man. Neuropsychologia, 28, 1021-1034.

Owen, A. M., Doyon, J., Petrides, M., \& Evans, A. (1996). Planning and spatial working memory: A positron emission tomography in humans. European Journal of Neuroscience, 8, 353-364.

Owen, A. M., Evans, A. C., \& Petrides, M. (1996). Evidence for a two-stage model of spatial working memory processing within the lateral frontal cortex: A positron emission tomography study. Cerebral Cortex, 6, 31-38.

Owen, A. M., Herrod, N. J., Menon, D. K., Clark, J. C., Downey, S. P., Carpenter, T. A., Minhas, P. S., Turkheimer, F. E. Williams, E. J., Robbins, T. W., Sahakian, B. J., Petrides, M., \& Pickard, J. D. (1999). Redefining the functional organization of working memory processes within human lateral prefrontal cortex. European Journal of Neuroscience, 11, 567-574.

Pandya, D. N., \& Barnes, C. L. (1987). Architecture and connections of the frontal lobe. In E. Perecman (Ed.), The frontal lobes revisited (pp. 41-72). New York: IRBN.

Perlmutter, J. S., Powers, W. J., Herscovitch, P., Fox, P. T., \& RAICHLE, M. E. (1987). Regional asymmetries of cerebral blood flow, blood volume, and oxygen utilization and extraction in normal subjects. Journal of Cerebral Blood Flow \& Metabolism, 7, 64-67.

Petrides, M. (1991). Monitoring of selections of visual stimuli and the primate frontal cortex. Proceedings of the Royal Society of London: Series B, 246, 293-298.

Petrides, M. (1994). Frontal lobes and behaviour. Current Opinion in Neurobiology, 4, 207-211.

PETRIDEs, M. (1995). Functional organization of the human frontal cortex for mnemonic processing: Evidence from neuroimaging studies. In J. Grafman, K. J. Holyoak, \& F. Boller (Eds.), Structure and functions of the human prefrontal cortex (Annals of the New York Academy of Sciences, Vol. 769, pp. 85-96). New York: New York Academy of Sciences.

Petrides, M. (1996). Lateral frontal cortical contribution to memory. Seminars in the Neurosciences, 8, 57-63.

Petrides, M., Alivisatos, B., \& Evans, A. C. (1995). Functional activation of the human ventrolateral frontal cortex during mnemonic retrieval of verbal information. Proceedings of the National Academy of Sciences, 92, 5803-5807.

Petrides, M., Alivisatos, B., Meyer, E., \& Evans, A. C. (1993). Functional activation of the human frontal cortex during the performance of verbal working memory tasks. Proceedings of the National Academy of Sciences, 90, 878-882.

Petrides, M., \& Milner, B. (1982). Deficits on subject-ordered tasks after frontal and temporal lobe lesions in man. Neuropsychologia, 20, 601-614.

Petrides, M., \& Pandya, D. N. (1994). Comparative architectonic analysis of the human and the macaque frontal cortex. In F. Boller \& J. Grafman (Eds.), Handbook of neuropsychology (Vol. 9, pp. 17-58). Amsterdam: Elsevier.

Prabhakaran, V., Smith, J. A., Desmond, J. E., Glover, G. H., \& GaBRIELI, J. D. (1997). Neural substrates of fluid reasoning: An fMRI study of neocortical activation during performance of the Raven's Progressive Matrices Test. Cognitive Psychology, 33, 43-63.

Ragland, J. D., Gur, R. C., Glahn, D. C., Censits, D. M., Smith, R. J., Lazarev, M. G., Alavi, A., \& Gur, R. E. (1998). Frontotemporal cerebral blood flow change during executive and declarative memory tasks in schizophrenia: A positron emission tomography study. Neuropsychology, 12, 399-413.

Rao, S. M., Bobholz, J. A., Hammeke, T. A., Rosen, A. C., Woodley, S. J., Cunningham, J. M., Cox, R. W., Stein, E. A., \& Binder, J. R. (1997). Functional MRI evidence for subcortical participation in conceptual reasoning skills. NeuroReport, 8, 1987-1993.
Robiss, T. W. (1996). Dissociating executive functions of the prefrontal cortex. Philosophical Transactions of the Royal Society of London: Series B, 351, 1463-1470.

Robinson, A. L., Heaton, R. K., Lehman, R. A., \& Stilson, D. W. (1980). The utility of the Wisconsin Card Sorting Test in detecting and localizing frontal lobe lesions. Journal of Consulting \& Clinical Psychology, 48, 605-614.

Rolls, E. T. (1996). The orbitofrontal cortex. Philosophical Transactions of the Royal Society of London: Series B, 351, 1433-1443.

ROSENKILDE, C. E. (1979). Functional heterogeneity of the prefrontal cortex in the monkey: A review. Behavioral \& Neural Biology, 25, 301-345.

RugG, M. D., Fletcher, P. C., Allan, K., Frith, C. D., Frackowiak, R. S., \& Dolan, R. J. (1998). Neural correlates of memory retrieval during recognition memory and cued recall. NeuroImage, 8, 262-273.

RugG, M. D., Fletcher, P. C., Frith, C. D., Frackowiak, R. S. J., \& Dolan, R. J. (1996). Differential activation of the prefrontal cortex in successful and unsuccessful memory retrieval. Brain, 119, 2073-2083.

RugG, M. D., Fletcher, P. C., Frith, C. D., Frackowiak, R. S. J., \& DolaN, R. J. (1997). Brain regions supporting intentional and incidental memory: A PET study. NeuroReport, 8, 1283-1287.

Rypma, B., Prabhakaran, V., Desmond, J. E., Glover, G. H., \& GABRIELI, J. D. (1999). Load-dependent roles of frontal brain regions in the maintenance of working memory. NeuroImage, 9, 216-226.

Schacter, D. L., Alpert, N. M., Savage, C. R., Rauch, S. L., \& Al BERT, M. S. (1996). Conscious recollection and the human hippocampal formation: Evidence from positron emission topography. Proceedings of the National Academy of Sciences, 93, 321-325.

Schacter, D. L., Curran, T., Galluccio, L., Milberg, W. P., \& BATES, J. F. (1996). False recognition and the right frontal lobe: A case study. Neuropsychologia, 34, 793-808.

Shallice, T. (1982). Specific impairments of planning. Philosophical Transactions of the Royal Society of London: Series B, 298, 199-209.

Shallice, T., \& Burgess, P. W. (1991a). Deficits in strategy application following frontal lobe damage in man. Brain, 114, 727-741.

Shallice, T., \& Burgess, P. W. (1991b). Higher-order cognitive impairments and frontal lobe lesions in man. In H. S. Levin, H. M. Eisenberg, \& A. L. Benton (Eds.), Frontal lobe function and dysfunction (pp. 125-138). New York: Oxford University Press.

Shallice, T., Burgess, P. W., Schon, F., \& Baxter, D. M. (1989). The origins of utilization behaviour. Brain, 112, 1587-1598.

Shallice, T., \& Evans, M. E. (1978). The involvement of the frontal lobes in cognitive estimation. Cortex, 14, 294-303.

Shallice, T., Fletcher, P., Frith, C. D., Grasby, P., Frackowiak, R. S. J., \& Dolan, R. J. (1994). Brain regions associated with acquisition and retrieval of verbal episodic memory. Nature, 368, 633-635.

SMITH, E. E., JoNides, J., \& KoEPPE, R. A. (1996). Dissociating verbal and spatial working memory using PET. Cerebral Cortex, 6, 11-20.

SMITH, M. L., \& MiLNER, B. (1988). Estimation of frequency of occurrence of abstract designs after frontal or temporal lobectomy. Neuro psychologia, 26, 297-306.

SQUIRE, L. R., \& COHEN, N. J. (1982). Remote memory, retrograde amnesia and the neuropsychology of memory. In L. S. Cermak (Ed.), Human memory and amnesia (pp. 275-303). Hillsdale, NJ: Erlbaum.

STERNBERG, S. (1966). High-speed scanning in human memory. Science, 153, 652-654.

Stone, M., Seger, C. A., Prabhakaran, V., Gabrieli, J. D. E., \& GLover, G. H. (1998, June). Studying privileged access with functional MRI. Paper presented at the Neural Correlates of Consciousness Conference, Bremen, Germany.

Stuss, D. T., Alexander, M. P., Lieberman, A., \& Levine, H. (1978) An extraordinary form of confabulation. Neurology, 28, 1166-1172.

Stuss, D. T., \& BENSON, D. F. (1986). The frontal lobes. New York: Raven.

STUSS, D. T., Eskes, G. A., \& Foster, J. K. (1994). Experimental neuropsychological studies of frontal lobe functions. In F. Boller \& J. Grafman (Eds.), Handbook of neuropsychology (Vol. 9, pp. 149-185). Amsterdam: Elsevier.

Talairach, J., \& Tournoux, P. (1988). Co-planar stereotaxic atlas of the human brain. Stuttgart: Thieme.

Tulving, E., Kapur, S., Markowitsch, H. J., Craik, F. I. M., Habib, R., \& Houle, S. (1994). Neuroanatomical correlates of re- 
trieval in episodic memory: Auditory sentence recognition. Proceedings of the National Academy of Sciences, 91, 2012-2015.

Tulving, E., Markowitch, H. J., Craik, F. I. M., Habib, R., \& Houle, S. (1996). Novelty and familiarity activations in PET studies of memory encoding and retrieval. Cerebral Cortex, 6, 71-79.

VILKKI, J., \& HoLST, P. (1991). Mental programming after frontal lobe lesions: Results on digit symbol performance with self-selected goals. Cortex, 27, 203-211.

VoGT, O. (1906). Über strukturelle Hirnzentra, mit besonderer Berücksichtigung der strukturellen Felder des Cortex pallii [On the structural centers of the brain, with particular emphasis on the structural regions of the cortex]. Anatomischer Anzeiger, 20, 74-114.

Wagner, A. D., Desmond, J. E., Glover, G. H., \& Gabrieli, J. D. (1998). Prefrontal cortex and recognition memory. Functional-MRI evidence for context-dependent retrieval processes. Brain, 121, 1985-2002.
Wheeler, M. A., Stuss, D. T., \& Tulving, E. (1995). Frontal lobe damage produces episodic memory impairment. Journal of the International Neuropsychological Society, 1, 525-536.

Worsley, K. J., Marrett, S., Neelin, P., \& Evans, A. C. (1996). Searching scale space for activation in PET images. Human Brain Mapping, 4, 74-90.

Zarahn, E., Aguirre, G. K., \& D'Esposito, M. (1997). Empirical analyses of BOLD fMRI statistics: I. Spatially unsmoothed data collected under null-hypothesis conditions. Neurolmage, 5, 179-197.

(Manuscript received November 22, 1999; revision accepted for publication April 12, 2000.) 